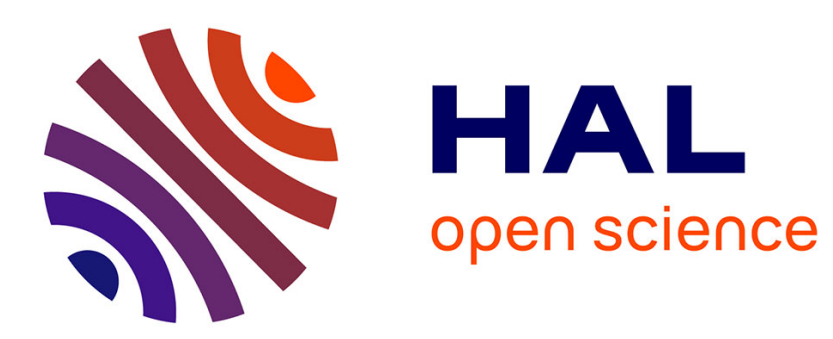

\title{
Predicting Transverse Mixing Efficiency Downstream of a River Confluence
}

S. Pouchoulin, Jérôme Le Coz, Emmanuel Mignot, L. Gond, N. Riviere

\section{To cite this version:}

S. Pouchoulin, Jérôme Le Coz, Emmanuel Mignot, L. Gond, N. Riviere. Predicting Transverse Mixing Efficiency Downstream of a River Confluence. Water Resources Research, 2020, 56 (10), 10.1029/2019WR026367 . hal-03127437

\section{HAL Id: hal-03127437 \\ https://hal.science/hal-03127437}

Submitted on 1 Feb 2021

HAL is a multi-disciplinary open access archive for the deposit and dissemination of scientific research documents, whether they are published or not. The documents may come from teaching and research institutions in France or abroad, or from public or private research centers.
L'archive ouverte pluridisciplinaire HAL, est destinée au dépôt et à la diffusion de documents scientifiques de niveau recherche, publiés ou non, émanant des établissements d'enseignement et de recherche français ou étrangers, des laboratoires publics ou privés. 


\section{Water Resources Research}

\section{RESEARCH ARTICLE \\ 10.1029/2019WR026367 \\ Predicting Transverse Mixing Efficiency Downstream of a River Confluence}

Key Points:

- Three high-resolution surveys of mixing are conducted downstream of a medium-sized, symmetrical, low-angle river confluence

- Shear-dominated transverse mixing can be predicted analytically and implemented in 1-D hydrodynamical models

- Various criteria are tested to predict vertical stratification due to density effects, inducing apparently rapid mixing

Correspondence to:

S. Pouchoulin and J. Le Coz, sebastien.pouchoulin@insa-lyon.fr; jerome.lecoz@inrae.fr

Citation:

Pouchoulin, S., Le Coz, J., Mignot, E., Gond, L., \& Riviere, N. (2020). Predicting transverse mixing efficiency downstream of a river confluence. Water Resources Research, 56, e2019WR026367. https://doi.org/ 10.1029/2019WR026367

Received 25 SEP 2019 Accepted 21 JUL 2020 Accepted article online 26 JUL 2020

2020. American Geophysical Union. All Rights Reserved.

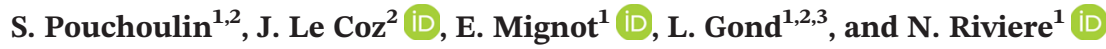 \\ ${ }^{1}$ Université de Lyon, INSA Lyon, Ecole Centrale de Lyon, Université Claude Bernard Lyon I, CNRS, Laboratoire de \\ Mécanique des Fluides et d'Acoustique, Villeurbanne, France, ${ }^{2}$ INRAE, UR RiverLy, River Hydraulics, Villeurbanne, \\ France, ${ }^{3} \mathrm{CEA}$, DEN, Cadarache, DTN, SMTA, Laboratoire de Modélisation des Transferts dans l'Environnement, Saint- \\ Paul-lez-Durance, France
}

\begin{abstract}
Predicting mixing processes, especially transverse mixing, downstream of river confluences, is necessary for assessing and modeling the fate of pollutants transported in river networks, but it is still challenging. Typically, there is a lack of transverse mixing solutions implemented in 1-D hydrodynamical models widely used in river engineering applications. To investigate the mixing processes developing downstream of a medium-sized river confluence, three high-resolution in situ surveys are conducted at the Rhône-Saône confluence in France, based on geolocated specific conductivity and hydroacoustic measurements. Contrasting mixing situations are observed depending on hydrological conditions. In some cases, the two flows mix slowly due to turbulent shear at their vertical interface. This can be modeled by an analytical solution of the advection-diffusion equation. In other cases, the waters from one of the two tributaries move under the waters of the other tributary. The induced local circulation enhances transverse mixing but not vertical mixing and the flow remains stratified vertically, which may be missed when surface or satellite images are analyzed qualitatively. Stratification may be predicted by comparing the time scales for shear and density-driven adjustment. Shear-dominated transverse mixing of depth-averaged concentrations can be predicted analytically and implemented in 1-D hydrodynamical models. However, the initiation of apparently rapid transverse mixing due to density-driven circulation remains to be better understood and quantified.
\end{abstract}

Plain Language Summary Predicting how waters mix downstream of river confluences is necessary for assessing and modeling the fate of pollutants transported in river networks, but it is still challenging. Typically, there is a lack of transverse mixing solutions implemented in models widely used in river engineering applications. To investigate the mixing processes developing downstream of a medium-sized river confluence, three high-resolution in situ surveys are conducted at the Rhône-Saône confluence in France. Contrasting slow or rapid mixing situations are observed depending on hydrological conditions. The transverse mixing of depth-averaged concentrations can be predicted analytically and implemented in 1-D hydrodynamical models. However, the initiation of rapid transverse mixing due to difference in fluid density remains to be better understood and quantified.

\section{Introduction}

Assessing the dispersion of solutes and suspended particulate matter in rivers is important for predicting the dissemination and mitigation of pollutants downstream of their sources, hence their sanitary and ecological impacts (Beltaos, 1979, 1980). The pollutants are mixed through the combined effects of molecular diffusion (usually negligible), turbulent diffusion, and advection by secondary current structures (Rutherford, 1994). As pollutants are mixed over the flow depth (vertical mixing), over the river width (transverse mixing) and along the river axis (longitudinal mixing), they spread over larger water volumes and their local concentration decreases. In shallow flows such as rivers and streams, transverse mixing is critical to reach concentration homogeneity throughout the water body (Constantinescu et al., 2016). The estimation of transverse mixing coefficients is necessary to predict the length required for the complete mixing of waters downstream of a confluence or a point source, as well as the impact on water intakes located on the river banks and the distribution of fluxes at further bifurcations, for instance. This study focuses on mixing downstream of river confluences. 
In river engineering applications, 1-D or 2-D hydrodynamic models are commonly used to predict pollutant fate and dynamics by solving the shallow water equations coupled with the advection-diffusion equation for solutes or suspended particulate matter (SPM; e.g., Beltaos \& Arora, 1988; Launay et al., 2019). One-dimensional models are especially useful for simulations over large river domains (e.g., El Kadi Abderrezzak et al., 2015; Launay et al., 2019). However, 1-D hydrodynamic models coupled with the 1-D advection-diffusion equation consider only cross-section averaged concentrations and assume complete mixing to occur instantaneously at each confluence. We have no example of a correction for incomplete lateral mixing applied to a 1-D hydrodynamic model. This assumption is unsatisfactory for modeling branched river networks, as complete mixing is known to take tens to hundreds of kilometers downstream of confluences of medium to large rivers (e.g., Bouchez et al., 2010; Lane et al., 2008; Rathbun \& Rostad, 2004; Umar et al., 2018).

Defining analytical or numerical solutions of the 2-D advection-diffusion equation to predict the lateral distribution of concentration downstream of a confluence is problematic due to the complexity of near-field mixing processes (Moody, 1995). Transverse mixing due to molecular diffusion is usually negligible compared to shear dispersion and advective effects over a range of spatial scales. Mixing is due firstly to the shear between the two incoming flows, characterized by turbulent eddies that develop at the mixing layer scale (Biron et al., 2019) and substantially enhance transverse mixing in the near-field downstream of the confluence. In addition to shear dispersion, mixing may be enhanced by convective effects due to large-scale, persistent flow structures, notably, helical motion and upwelling motion. As identified by Rhoads and Kenworthy (1995) in a small, high-angle confluence, contra-rotating helical motion may develop within each inflow downstream of the confluence (Bradbrook et al., 2001; Lane et al., 2000; Lewis \& Rhoads, 2015), due to the reciprocal curvature of the flow streamlines. Recent field experiments by Sukhodolov and Sukhodolova (2019) have used theory of flow through bends to predict documented patterns of helical motion at confluences. On the other hand, upwelling motion (Lane et al., 2008) occurs when one confluent flow rides over the other (Pouchoulin et al., 2018; Shakibainia et al., 2010), possibly over the full width of the downstream channel. The factors that initiate and enhance both helical and upwelling motions are still not fully understood. They likely include the geometrical characteristics of the confluence: Helical motion is especially pronounced at high-angle confluences and bed discordance can produce patterns of upwelling (Biron et al., 1996, 2004).

Helical motion has been shown to have a strong effect on mixing (Lewis \& Rhoads, 2015; Rhoads, 1996; Rhoads \& Kenworthy, 1995; Rhoads \& Sukhodolov, 2001) and the same is true for upwelling motion (Biron et al., 1996, 2004). In essence, 1-D hydrodynamic models cannot solve such 3-D advective mechanisms, which limits their application to flux simulation in branched river networks. The only way to accommodate these important advective effects is to lump them in the transverse mixing coefficient of the 1-D advection-diffusion equation and calibrate its value using field observations. Clearly, changes in the momentum, velocity, or density ratios between both inflows and other hydrologically determined factors also play a role as slow or rapid mixing situations may be observed at the same site for different hydrological conditions, as reported by Rhoads and Kenworthy (1995) and Lewis and Rhoads (2015) for the Kaskaskia-Copper Slough confluence, by Lane et al. (2008) for the Paraná-Paraguay confluence, and Gualtieri et al. (2018) for the Negro-Solimões (Amazon) confluence, for instance.

Slow mixing due to the nearly vertical shear layer developing between the two confluent flows can be modeled following well-established solutions of the 2-D advection-diffusion equation (Fischer et al., 1979; Rutherford, 1994), extended to laterally heterogeneous flows by the stream-tube approach developed by Yotsukura and Sayre (1976) and Beltaos (1979). However, experimental calibration of the mixing parameters and validation of mixing models have been seldom conducted in situ since the 1980s. To the best of our knowledge, Rathbun and Rostad (2004) have presented the only recently published tracing experiment with application of the stream-tube model for transverse mixing (downstream of the Mississippi-Ohio confluence). However, their survey did not focus on the near-field section downstream of the confluence, and the resolution of their current-meter measurements and tracer sampling does not provide a detailed insight on mixing processes throughout the explored cross sections. Moody (1995) did provide observations of mixing processes in the near field of the Mississippi and St. Croix confluence but with similar measurement limitations and no application of a mixing model. 
On the other hand, many authors have recently investigated the mixing processes downstream of confluences of small (Rhoads \& Sukhodolov, 2001), medium (Herrero et al., 2018), to very large (Gualtieri et al., 2019; Lane et al., 2008; Laraque et al., 2009) rivers using modern measurement techniques, especially high-resolution multibeam echosounders and hydroacoustic velocity profilers. However, no reliable and accurate tracing of the waters is available with high resolution: Mixing was assessed either from sky based on spectral response (Umar et al., 2018), using low-resolution tracer sampling (Bouchez et al., 2010) or vertical electrical conductivity profiles (Herrero et al., 2018) over a few locations throughout each cross section, or based on acoustically derived suspended sediment concentration with high spatial resolution but usually large uncertainties and difficult interpretation due to local bed-material resuspension (Gualtieri et al., 2019; Lane et al., 2008; Rhoads \& Johnson, 2018). Such research efforts have provided extremely valuable insights on the mixing processes downstream of river confluences and on the typical values of complete mixing lengths. However, their findings were not systematically used to evaluate existing analytical transverse mixing solutions (as done by Rathbun \& Rostad, 2004, and earlier works by Yotsukura, Beltaos, and others in the 1970s to 1980s), let alone to develop and improve them. On the other hand, high-resolution numerical studies using computational fluid dynamics simulations (e.g., Cheng \& Constantinescu, 2018; Constantinescu et al., 2016; Horna Munoz et al., 2020; Lyubimova et al., 2014; Shakibainia et al., 2010) have brought detailed insight on mixing processes downstream of confluences but their computational cost is still too high for engineering applications to large river domains.

This paper reports a new evaluation of near-field mixing processes downstream of a medium-sized, symmetrical, low-angle confluence and explores the applicability of analytical transverse mixing solutions, which could be used in 1-D hydrodynamical models to improve the distribution of solute and SPM fluxes throughout branched river networks. This experimental research is based on high-resolution field surveys conducted for various hydrological conditions in the near field of the Rhône-Saône confluence in France. Section 2 summarizes the theory and expression of an analytical transverse mixing model applicable to river confluences. Section 3 presents the experimental site and measurement techniques. Section 4 presents the observations of velocity, concentration, and mixing. Section 5 then analyses these results in light of the model and provides corresponding values of the mixing coefficients. Section 6 finally provides a discussion of the causes for rapid mixing, its prediction and associated stratification effects, and the potential for improving sediment and pollutant concentration predictions in 1-D hydrodynamical models of branched river networks.

\section{Analytical Solutions for Transverse Mixing: Application to River Confluences}

\subsection{Two-Dimensional Mixing Equation and Transverse Mixing Coefficient}

The study focuses on the mixing of two rivers merging at a confluence. The discharges and passive scalar concentrations of the two incoming rivers evolve with characteristic time scales of several hours, typically. The flow and concentration fields are thus considered steady, as opposed to the case of sudden releases such as accidental pollutions. Therefore, longitudinal dispersion effects are neglected.

The two incoming rivers are assumed to have homogeneous concentrations. Considering that they flow side by side after they have merged at the confluence (this assumption will be discussed in the following sections), no vertical diffusion is considered. The study thus simplifies in a two-dimensional problem, along the longitudinal and transverse directions, with two flows of homogeneous concentrations set in contact through a vertical boundary. In such a case, the depth-averaged turbulent advection-diffusion equation of a passive scalar within the flow reads (Fischer et al., 1979; Rutherford, 1994):

$$
\frac{\partial\left(u_{x, d} h c\right)}{\partial x}+\frac{\partial\left(u_{y, d} h c\right)}{\partial y}=\frac{\partial\left(h \varepsilon_{y, d} \frac{\partial c}{\partial y}\right)}{\partial y}
$$

where $x$ is the longitudinal streamwise direction (with $x=0$ at the upstream boundary condition), $y$ is the transverse direction, $u_{x, d}$ and $u_{y, d}$ are the time- and depth-averaged velocity components in the two directions $x$ and $y$, respectively, $h$ is the water depth, $c$ is the time- and depth-averaged passive scalar concentration whose units depend on the passive scalar considered, and $\varepsilon_{y, d}$ is the time- and depth-averaged transverse mixing coefficient $\left(\mathrm{m}^{2} / \mathrm{s}\right)$ that accounts for both the depth-averaged transverse turbulent diffusion and for the convective dispersion by secondary currents (Rutherford, 1994; Yotsukura \& Sayre, 1976). 
Table 1

Experimental Conditions for the Three Surveys on the Rhône-Saône Confluence (See Text for Definition of Variables)

\begin{tabular}{llccc}
\hline & \multicolumn{1}{c}{ Date of the event } & $2018-03-08$ & $2018-05-17$ & $2018-10-09$ \\
\hline \multirow{2}{*}{ Rhône River (main inflow) } & Temperature $T_{\text {main }}\left({ }^{\circ} \mathrm{C}\right)$ & 7.2 & 14.0 & 18.3 \\
& Conductivity $(\mu \mathrm{S} / \mathrm{cm})$ & 560 & 475 & 480 \\
& SPM concentration $(\mathrm{g} / \mathrm{L})$ & 0.009 & 0.014 & 0.000 \\
& Density $\rho_{\text {main }}\left(\mathrm{kg} / \mathrm{m}^{3}\right)$ & 999.9 & 999.4 & 998.7 \\
& Wetted area $\left(\mathrm{m}^{2}\right)$ & 1,628 & 1,643 & 1,564 \\
& Discharge $Q_{\text {main }}\left(\mathrm{m}^{3} / \mathrm{s}\right)$ & 904 & 855 & 164 \\
& Mean velocity $U_{\text {main }}(\mathrm{m} / \mathrm{s})$ & 0.555 & 0.520 & 0.105 \\
Saône River (tributary) & Temperature $T_{\text {trib }}\left({ }^{\circ} \mathrm{C}\right)$ & 5.8 & 16.5 & 18.0 \\
& Conductivity $\left(\mu \mathrm{S} / \mathrm{cm}^{2}\right)$ & 680 & 740 & 980 \\
& SPM concentration $(\mathrm{g} / \mathrm{L})$ & 0.024 & 0.023 & 0.000 \\
& Density $\rho_{\text {trib }}\left(\mathrm{kg} / \mathrm{m}^{3}\right)$ & 1000.0 & 999.0 & 998.8 \\
& Wetted area $\left(\mathrm{m}^{2}\right)$ & 834 & 860 & 869 \\
& Discharge $Q_{\text {trib }}\left(\mathrm{m}^{3} / \mathrm{s}\right)$ & 694 & 768 & 92 \\
& Mean velocity $U_{\text {trib }}(\mathrm{m} / \mathrm{s})$ & 0.833 & 0.893 & 0.106 \\
Confluence (downstream & Mean velocity $\boldsymbol{U}(\mathbf{m} / \mathbf{s})$ & $\mathbf{0 . 6 0 1}$ & $\mathbf{0 . 6 2 7}$ & $\mathbf{0 . 0 9 6}$ \\
reach) & Width $\boldsymbol{b}(\mathbf{m})$ & $\mathbf{2 7 4}$ & $\mathbf{2 7 5}$ & $\mathbf{2 7 0}$ \\
& Depth $\boldsymbol{H}(\mathbf{m})$ & $\mathbf{9 . 2 3}$ & $\mathbf{9 . 0 1}$ & $\mathbf{9 . 3 9}$ \\
& Momentum ratio $\boldsymbol{M}^{*}$ & $\mathbf{1 . 1 5}$ & $\mathbf{1 . 5 4}$ & $\mathbf{0 . 5 6}$ \\
& Relative density difference $\boldsymbol{\Delta} \boldsymbol{\rho}^{*}$ & $\mathbf{- 6 . 2 1} \times \mathbf{1 0}$ & $\mathbf{3 . 1 8} \times \mathbf{1 0}$ & $\mathbf{- 4 . 6 9} \times \mathbf{1 0}$ \\
& Velocity shape factor $\boldsymbol{\mathbf { - 5 }}$ & $\mathbf{1 . 1 0}$ & $\mathbf{1 . 1 3}$ & $\mathbf{1 . 0 9}$ \\
\hline
\end{tabular}

Note. Values in bold font characterize the downstream reach of the confluence.

Yotsukura and Cobb (1972) proposed to change the transverse distance variable $y$ to the cumulative discharge $q=\int_{0}^{y} u_{x, d}(\eta) h(\eta) d \eta$ ranging from $q=0$ (left bank) to $q=Q=Q_{\text {main }}+Q_{\text {trib }}$ (right bank), with $Q$ the total discharge and $Q_{\text {main }}$ and $Q_{\text {trib }}$ the upstream discharges of the main inflow and of the tributary, respectively. Considering the cross-sectional averaged values for the transverse mixing coefficient $\varepsilon_{y, c s}$, streamwise velocity $u_{c s}$ and water depth $h_{c s}$, Equation 1 then reads, using the stream-tube model notations:

$$
\frac{\partial c}{\partial x}=\varepsilon_{y, c s} \psi_{c s} u_{c s} h_{c s}^{2} \frac{\partial^{2} c}{\partial q^{2}}
$$

where $\psi_{c s}=\frac{1}{Q u_{c s} h_{c s}^{2}} \int_{0}^{Q} u_{x, d}(q) h(q)^{2} d q$ is the cross-sectional velocity shape factor (Beltaos, 1980; Jung et al., 2019) which is equal to 1 for a fully homogeneous flow, with constant depth and velocity along the width. Cross-sectional velocity shape factor $\psi_{c s}$ is estimated from measurements of velocity and depth along the cross sections of the studied domain (Table 1).

Equation 2 can be used to predict the transverse mixing, hence the spatial distribution of any passive scalar depth-averaged concentration $c$, in flows with variable velocity and depth. The main unknown is the transverse mixing coefficient $\varepsilon_{y, c s}$ which depends on the flow turbulence and geometry (Gualtieri \& Mucherino, 2007; Rutherford, 1994).

\subsection{Analytical Solutions Providing the Concentration Field}

Analytical solutions of the transverse mixing equation (Equation 2) exist for various configurations of pollutant release, including point, line, or surface sources in an unbounded or bounded flow. At a confluence, the polluted tributary is a surface source with uniform pollutant concentration in a flow bounded by two lateral banks. The effect of the surface source is computed as a continuous sum of the effect of vertical line sources distributed side by side from $q=0$ to $q=Q_{\text {trib }}$. Making concentration $c$ dimensionless so that $c_{\text {trib }}=1$ in the tributary and $c_{\text {main }}=0$ in the main channel, the following solution of Equation 2 is adapted from Yotsukura and Cobb (1972) and Rathbun and Rostad (2004): 


$$
c_{0}\left(x-x_{0}, q\right)=\frac{1}{\sqrt{4 \pi \varepsilon_{y} \psi U H^{2}\left(x-x_{0}\right)}} \int_{0}^{Q_{t r i b}} \exp \left(-\frac{\left(q-q^{\prime}\right)^{2}}{4 \varepsilon_{y} \psi U H^{2}\left(x-x_{0}\right)}\right) d q^{\prime}
$$

which is the general equation for transverse mixing in an unbounded flow (i.e., with no banks) where depth $H$, velocity $U$, velocity shape factor $\psi$, and transverse mixing coefficient $\epsilon_{y}$ in Equation 3 are reach-averaged quantities. The integral sum between $q=0$ and $q=Q_{\text {trib }}$ represents the surface source that constitutes the "polluted" tributary.

In a bounded flow, the effects of the banks can be accounted for by applying the method of mirrors:

$$
\left\{\begin{array}{c}
c\left(x-x_{0}, q\right)=c_{0}\left(x-x_{0}, \pm q\right)+\sum_{n=1}^{N} c_{n}\left(x-x_{0}, q\right) \\
\text { For } n>0, c_{n}\left(x-x_{0}, q\right)=\frac{1}{\sqrt{4 \pi \varepsilon_{y} \psi U H^{2}\left(x-x_{0}\right)}} \int_{0}^{Q_{t r i b}} \exp \left(-\frac{\left( \pm 2 n Q+q \pm q^{\prime}\right)^{2}}{4 \varepsilon_{y} \psi U H^{2}\left(x-x_{0}\right)}\right) d q^{\prime}
\end{array}\right.
$$

where $c_{0}\left(x-x_{0}, \pm q\right)$ is the sum of the solution $c_{0}\left(x-x_{0}, q\right)$ of the real source and the solution $c_{0}\left(x-x_{0},-q\right)$ of its first reflection across the right bank $(q=0)$. For $n>0$, each $c_{n}\left(x-x_{0}, q\right)$ adds the solutions of the next four reflections, two across the right bank $(q=0)$ and two across the left bank $(q=Q)$. Therefore, the combined solution $c\left(x-x_{0}, q\right)$ as expressed in Equation 4 accounts for $4 N+1$ fictitious pollutant sources in addition to the real source. Through a convergence study, we found that including the 11 fictitious sources closest to the real source was enough, as additional fictitious sources have a negligible influence on the results.

For confluences, the longitudinal position $x_{0}$ of the pollution source, as included in previous equations, does not necessarily coincide with the upstream cross section of the confluence $(x=0)$. Such a virtual origin (i.e., taking $x_{0} \neq 0$ ) is classically used in the description of mixing layers downstream of splitter plates, with either positive or negative values reported (e.g., Mehta, 1991).

When $x \rightarrow \infty$, the concentration $c$ asymptotically tends to its equilibrium uniform value $c_{\mathrm{u}}$, that is, the averaged concentration obtained when the two confluent flows are perfectly mixed:

$$
\frac{c_{u}}{c_{\text {trib }}}=\frac{c_{\text {trib }} Q_{\text {trib }}+c_{\text {main }} Q_{\text {main }}}{c_{\text {trib }}\left(Q_{\text {trib }}+Q_{\text {main }}\right)}=\frac{Q_{\text {trib }}}{Q}
$$

As visible from Equation 4, the higher the transverse mixing coefficient $\varepsilon_{y}$ is, the shorter the distance $x$ to reach the concentration $c_{u}$ will be. Another way to write these equations is to use the erf function, as described in Appendix A.

\subsection{Length for Complete Mixing $L_{m}$}

The transverse mixing coefficient $\varepsilon_{y}$ value is an indicator of the mixing efficiency. However, the efficiency can also be quantified through the so-called length for complete mixing: $L_{m}$. This is the distance required for the flow to recover a uniform concentration, which can be scaled to a characteristic flow length, usually the downstream branch width $b$ (Fischer et al., 1979; Rutherford, 1994). However, the asymptotic concentration $c_{u}$ can never be reached exactly. Hence, $L_{m}$ is usually defined as a length for a "sufficient mixing." The criterion widely used for that is the so-called " $5 \%$ criterion" proposed by Fischer et al. (1979) or Rutherford (1994) and used for confluence flows by Gaudet and Roy (1995). Mixing is considered complete (or sufficient) when all the concentration data measured in a cross section located at a distance $L_{m}$ downstream of the confluence are included within the $\left[0.95 c_{u} ; 1.05 c_{u}\right]$ interval; that is, local concentrations do not deviate by more than $\pm 5 \%$ from the cross-section average concentration. The length for complete mixing $L_{m}$ can be linked to the transverse mixing coefficient $\varepsilon_{y}$ (Fischer et al., 1979):

$$
\frac{L_{m}}{b}=\alpha \frac{U b}{\varepsilon_{y} \psi}
$$

where $\alpha$ is a coefficient which depends on the geometry and position of the point, line or surface source within the upstream cross section. The way to derive $\alpha$, far more complex for a surface source than for a line source, was described by Rutherford (1994) and is detailed in Appendix A. 


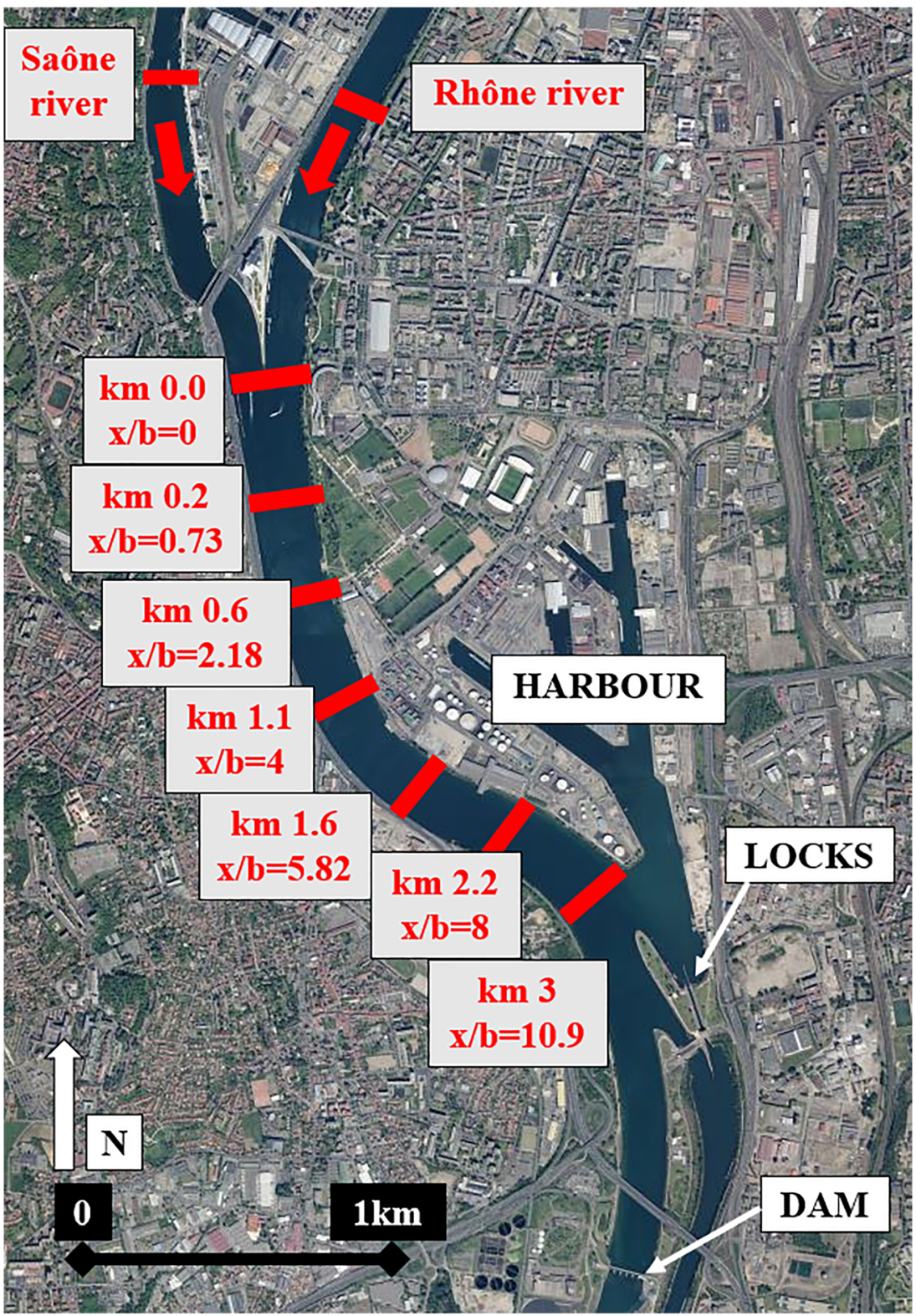

Figure 1. Aerial view of the Rhône-Saône confluence in Lyon, France. Measured cross sections are named by their distances from the confluence ( $x$, in kilometers) and their corresponding nondimensional distances $(x / b$ with $b$ the mean downstream channel width) (source of background image: geoportail.fr).

Equation 4 forms the 1-D advection-diffusion equation solution available to compute the mixing downstream of a confluence, with two alternative indicators of the mixing efficiency, $L_{m}$ and $\varepsilon_{y}$, linked by Equation 6. The next section details the field experiments devoted to test this model.

\section{Field Experiments: Confluence Site, Measurement Techniques and Selected Events}

3.1. The Rhône-Saône Confluence

The confluence between the Rhône and Saône Rivers is located in the inner city of Lyon, France (Figure 1). The Saône River is the main tributary of the Rhône River by mean discharge, with a length of $480 \mathrm{~km}$ from its source in the Jura Mountains to Lyon. The Rhône River takes its source in the Swiss Alps, crosses Lake Geneva, then goes from the French Alps to Lyon, the location of the present study; downstream, it finally 
flows into the Mediterranean Sea through a delta. Upstream of the confluence, the Saône River has a width of about $140 \mathrm{~m}$ and a mean depth of about $7 \mathrm{~m}$. The upper Rhône is about $180 \mathrm{~m}$ wide with a mean depth of about $10 \mathrm{~m}$. The banks of the two rivers are artificial upstream and downstream of the confluence, either lined with riprap or vertical concrete walls. A longitudinal, concrete spur designed to force a low-angle confluence separates the two rivers in the last few hundreds of meters. The actual beginning of the confluence and thus the Kilometer 0 of our study is defined as the location where this spur becomes submerged below the free surface; the submerged spur continues further downstream and is extended by three piers. Upstream of the apex of the confluence, there was a dam on the Saône River until it was decommissioned in 1966. Some foundations remain on the bottom of the river, inducing bed discordance between the Saône and the Rhône rivers at the confluence. The bed of the Saône River is about $5 \mathrm{~m}$ above that of the Rhône River.

The fluvial harbor of Lyon located at Kilometer 3.0 is the downstream limit of the studied domain. No measurement was performed downstream of its entrance because (i) this harbor might release some water with different electrical conductivity in the Rhône River and (ii) right after the harbor, a hydroelectrical facility including a dam, a plant, navigational locks, and a canal (cf. Figure 1) divides the flow in two branches. The Rhône River reach between the confluence and the fluvial harbor is approximately $275 \mathrm{~m}$ wide and $9 \mathrm{~m}$ deep, on average.

\subsection{Field Measurement Techniques and Procedures}

Electrical conductivity is a suitable tracer of the mixing processes downstream of the confluence of the Rhône and Saône Rivers. First, as the two river catchments have contrasting geological and land use conditions, their waters naturally show a noticeable difference of electrical conductivity. No injection of additional tracer is thus required, simplifying both ecological and regulatory considerations. Second, electrical conductivity is a conservative parameter (Gaspar, 1987), thus allowing identifying the mixing coefficient directly from its value within the range of the two upstream rivers. Last, electrical conductivity can be continuously recorded in situ using conventional conductivity-temperature-depth (CTD) loggers, as already done by Moody (1995), for instance. However, electrical conductivity is expressed as a specific conductance for a given reference temperature (here $25^{\circ} \mathrm{C}$ ), hence requiring concurrent temperature measurements for correction.

The measurements are conducted by four operators in an inflatable dinghy equipped with a 50hp Yamaha thermic engine. A combination of three onboard measurement techniques-a Lowrance Hook1 echo sounder, a Teledyne RDI $1200 \mathrm{kHz}$ RioGrande acoustic Doppler current profiler (ADCP) and a Leica real-time kinematic (RTK) GPS connected to the Orpheon network, providing a centimetric precision on the GPS position-jointly provides bathymetry profiles and velocity fields from the near bed to the near surface elevation. Four ADCP crossings are conducted at each cross section and three-dimensional flow patterns were analyzed using the VMT software (Parsons et al., 2013). The secondary flow vectors are computed in the frame of reference of the local depth-averaged velocities using the Rozovskii decomposition (cf. Rhoads \& Kenworthy, 1999).

The SPM concentration is measured from water samples taken near the surface of each tributary for each survey. SPM concentration is also recorded in each tributary at turbidity stations operated by the Rhône sediment observatory (Poulier et al., 2019). Variations in discharge and SPM concentration recorded at the stations during each experiment are negligible.

Four Leveline CTD probes from Aquaread are used to measure the electrical conductivity. Each probe records, with a maximum data acquisition frequency of $1 \mathrm{~Hz}$, the electrical conductivity, temperature, and static pressure, the latter giving the depth of immersion of the probe. These probes record up to 500,000 measurements. According to manufacturer's specifications, the probes have a $1 \%$ accuracy on the electrical conductivity measurements, but uncertainties linked to the calibration of the probes raise this accuracy to about $5 \%$. Fluid density $\rho$ (in $\mathrm{g} / \mathrm{L}$ ) is calculated from the temperature $T$ (in ${ }^{\circ} \mathrm{C}$ ) and the suspended sediment concentration $C_{S P M}($ in $\mathrm{g} / \mathrm{L})$ of each tributary as $\rho=\left(a_{1} T+\ldots+a_{5} T^{5}\right) /(1+b T)+C_{S P M}$ where the values of coefficients $a 1 \ldots, a 5, b$ are given by Kell (1975). The four probes are fixed every $1 \mathrm{~m}$ along a Dacron fishing line and a $3 \mathrm{~kg}$ sounding weight is attached at the end of the line. The measurement strategy consists of exploring several cross sections of the Rhône River downstream of the confluence through successive crossings with the line attached to the boat and various immersion depths. As the probes extend over $4 \mathrm{~m}$ only along the 
line, several crossings are necessary to cover the full depth of the cross section. In order to avoid any collision with the river bed or obstacles, the heights of the probes above the river bed are visually controlled using the real-time display of the echo sounder: For the deepest crossing, an operator permanently adjusts the length of the line to follow the bottom as close as possible. The location of the probes can be known at each time step, thanks to the GPS and the pressure sensor of each CTD probe. Time differences between the probes, the GPS and the ADCP are checked during the field campaigns and the recorded data are synchronized in postprocessing by subtracting their mean difference from the GPS time taken as the reference.

Horizontal positions of the CTD probes are not corrected for the variable vertical angle of the probe line due to inertia and drag. The vertical angle is kept as small as possible in the transverse direction by adjusting the boat speed relative to the flow. As the probes are relatively small and the sounding weight is relatively heavy ( $3 \mathrm{~kg}$ ), the vertical angle is typically lower than $20^{\circ}$ in the transverse direction and lower than $15^{\circ}$ in the downstream direction, which corresponds to horizontal positioning errors of 5 and $4 \mathrm{~m}$, respectively, at a maximum depth of $15 \mathrm{~m}$. As the data are projected longitudinally, only the transverse positioning errors would affect the observed spatial pattern of conductivity measurements. The estimated errors ( $\sim 2 \%$ of the cross-sectional width) are small enough not to bias our representation of the mixing processes. This is visually confirmed as the conductivity patterns measured at different depths from successive, reciprocal transects are not substantially displaced in opposite directions based on which direction the boat was moving.

During the crossings, the boat has neither a perfectly constant speed nor an exactly straight trajectory. Consequently, the electrical conductivity measurements are not regularly spaced throughout a cross section. In postprocessing, the electrical conductivity is interpolated linearly between the points of measurements, in each cross section. For a given campaign, CTD probes measure the electrical conductivities and the ADCP measures the flow depths and velocities in the two upstream cross sections (in the Saône River and in the upstream Rhône River) and at least in five cross sections downstream of the confluence (cf. Figure 1). This provides the general hydraulic characteristics of each event detailed in the next section.

\subsection{Description of the Field Surveys}

Three experimental campaigns are performed on the Rhône-Saône confluence during the year 2018, which are referenced by their dates: 8 March, 17 May, and 9 October. They are characterized by quite different hydraulic conditions detailed in Table 1 . The 8 March event follows a discharge increase due to snowmelt, which explains the low water temperatures. The hydraulic conditions for 17 May are typical of the end of spring for this confluence, with discharges coming from the Saône and Rhône Rivers of about the same magnitude. The last experiment is typical of a drought, which from previous records appears about once a year.

For all the experiments, the electrical conductivity of the Saône River is the highest. The difference with the Rhône River is always greater than $100 \mu \mathrm{S} / \mathrm{cm}$, ensuring a sufficient contrast between the two waters. Moreover, the temperature difference does not exceed $2.5^{\circ} \mathrm{C}$, which is the maximum accepted difference to minimize temperature and specific conductivity errors due to the temperature inertia of the CTD probes. As already mentioned, the water density is calculated from the SPM concentration and the water temperature of each tributary. For 9 October experiments, the SPM concentration was too low to be detected. On this site, the water depth remains relatively constant whatever the discharge, due to the presence of a dam $4 \mathrm{~km}$ downstream of the confluence (cf. Figure 1). The aspect ratio $b / H$ downstream of the confluence is thus a constant for the three surveys. The connection between these general hydraulic characteristics and the river mixing processes is detailed in section 5.

\section{Results}

For 8 March, mixing is mainly transverse: The electrical conductivity of the water is nearly homogeneous vertically. Waters originating from the two tributaries are separated by a zone of intermediate values of conductivity that are indicative of a vertical mixing interface (Figure 2a). This is consistent with the velocity field in the various cross sections (Figure $2 b$ ): Transverse velocity components are quite weak $(<0.3 U)$, compared to the average velocity $U$ in the downstream reach. Some transverse velocity components appear to be connected to local variations of the bed profile but no large scale transverse motion is observed. Thus, as 
(a)
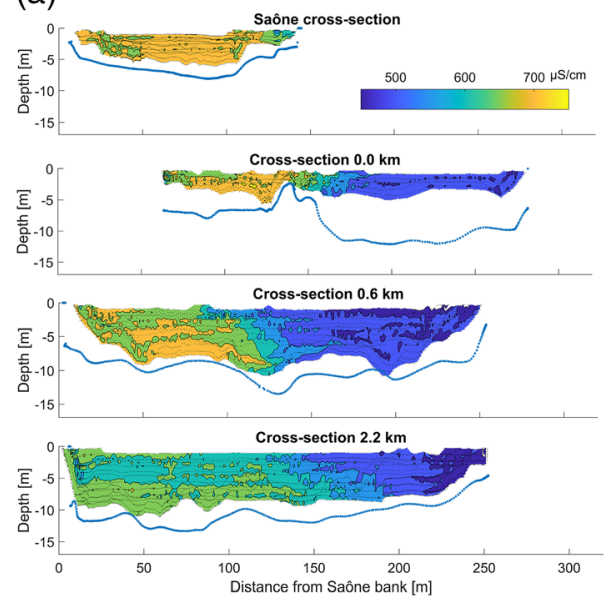

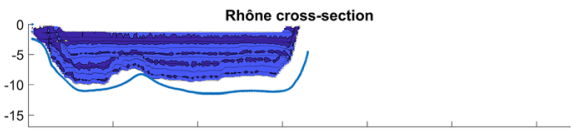

Cross-section $0.2 \mathrm{~km}$

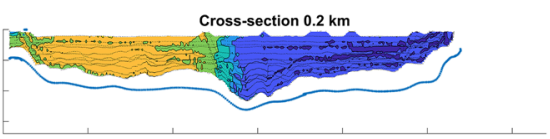

Cross-section $1.1 \mathrm{~km}$

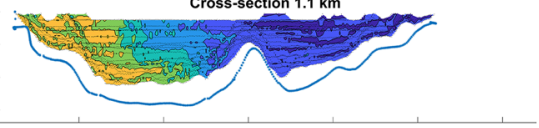

Cross-section $3.0 \mathrm{~km}$

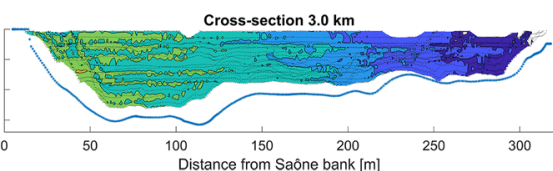

(b)
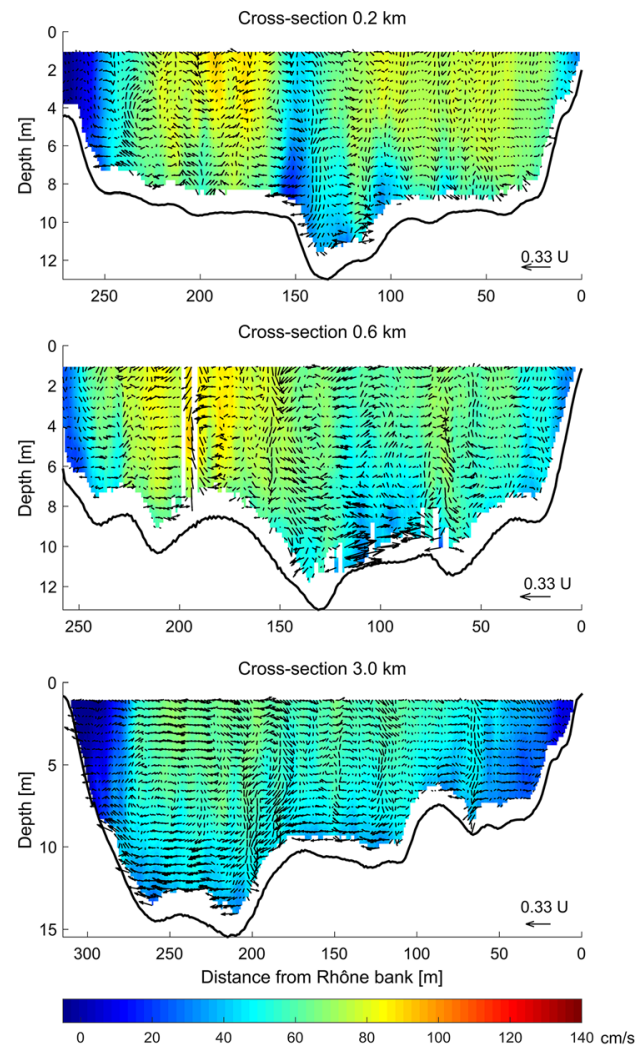

Figure 2. Measurements at various cross sections upstream and downstream of the Rhône-Saône confluence on 8 March (looking upstream, left bank on the right hand): (a) Conductivity contours. The blue and black dots represent the river bed and the measurement points, respectively. (b) Streamwise velocity with secondary flow vectors. Unmeasured areas, especially near the bed and the free surface, are displayed white.

expected for transverse mixing alone, the concentration gradient zone widens with distance from the confluence, and mixing increases.

The 17 May case is quite similar. The mixing interface is slightly inclined (Figure 3a) consistently with the velocity field. Indeed, a fairly strong helical motion is observed (Figure 3b). It appears to be confined to the immediate vicinity of the mixing interface; hence, it is not the channel-scale helical motion characteristic of flow curvature. The water coming from the Rhône River, which is colder and thus heavier, tends to pass below the warmer water coming from the Saône River. The combination of both the higher density 
(a)
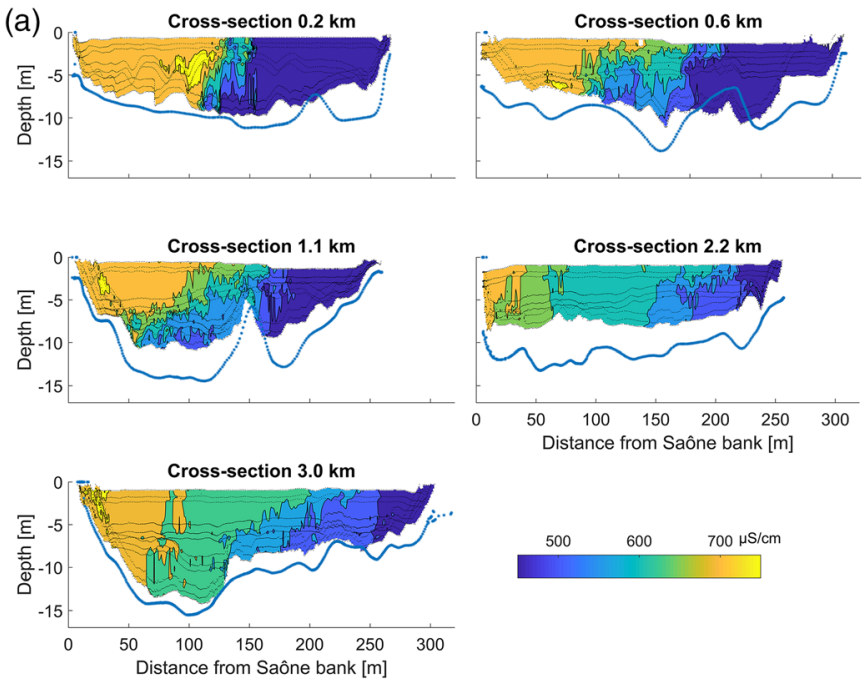

(b)
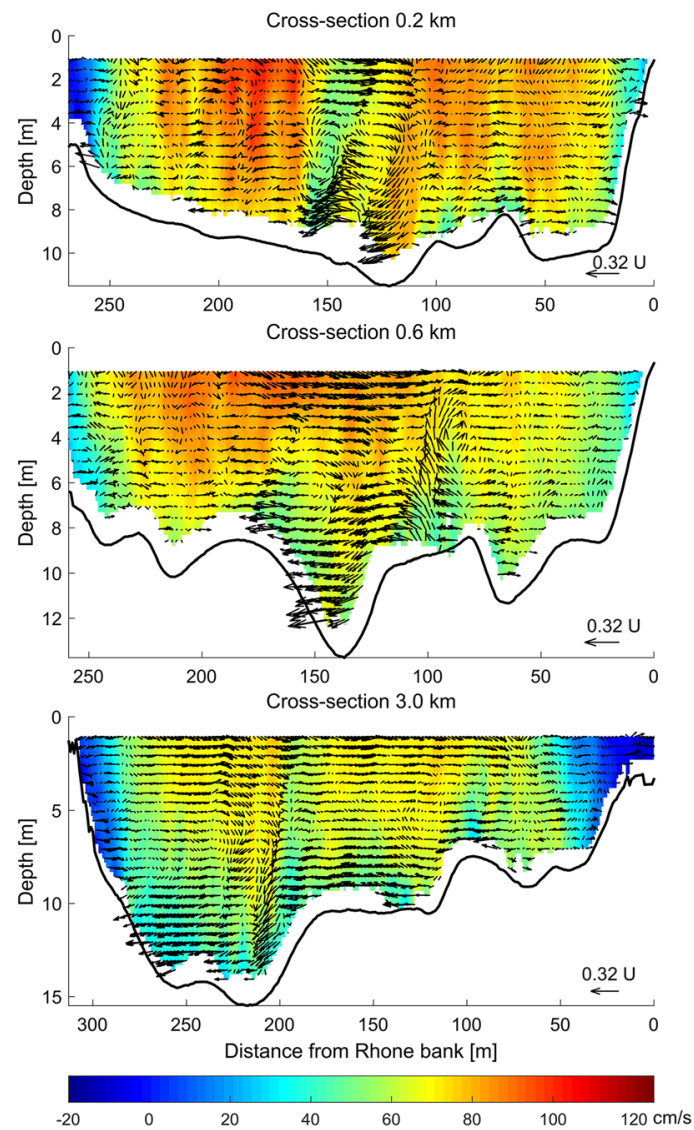

Figure 3. Measurements at various cross sections downstream of the Rhône-Saône confluence on 17 May (looking upstream, left bank on the right hand): (a) Conductivity contours. (b) Streamwise velocity with secondary flow vectors. No measurements were done on upstream cross sections during this survey. difference and a slightly higher momentum ratio $M^{*}=M_{\text {trib }} / M_{\text {main }}$ (cf. Table 1) could explain this orientation of the mixing layer. For the March survey, momentum ratio is closer to 1 and relative density difference is lower, which might be the reason why the mixing layer remains vertical.

Finally, the behavior for the 9 October event is quite different from the two others, as it is characterized by a strong vertical stratification. Indeed, the mixing interface (Figure 4a) is almost horizontal from the first cross section investigated $(0.2 \mathrm{~km})$. Water originating from the Saône River passes below the water coming from the Rhône River. This is consistent with the measured temperature difference: In this case, the Saône water is the coolest and the heaviest. This slumping motion is also consistent with the velocity field: At cross section located at $0.2 \mathrm{~km}$ (Figure $4 \mathrm{~b}$, top graph), fluid near the surface moves from right to left and fluid near the bed moves from left to right. Transverse velocities are of the same order of magnitude as $U$ : This means that the cross flow could be achieved after about one channel width, consistent with the stratification achieved between cross sections 0.2 and $0.6 \mathrm{~km}$. This secondary motion quickly weakens as the stratification is achieved (Figure 4b).

At this stage, the different mixing processes reported for these three field surveys appear difficult to explain from the direct comparison of basic criteria (cf. Table 1). The density differences in March and October are similar, but mixing is not: In March, the mixing layer is nearly vertical, whereas it is almost horizontal in October campaign. In October, the velocity difference, hence the shear dispersion, is much smaller, which may be why density difference has a greater impact and why the heaviest (coolest) flow rides under the other flow. Differences in momentum ratio $M^{*}$ may also play a role although it remains relatively close to 1 compared to the much wider range covered by cases reported in the literature. Local conditions related to channel bathymetry, especially bed discordance ( $5 \mathrm{~m}$ on an average depth of $10 \mathrm{~m}$ ) might also enhance upwelling motion and transverse mixing. However, opposite observations across the campaigns (the Saône River passing sometimes above, sometimes under the Rhône River) suggest that bed discordance is not the only factor driving the relative vertical positions of the two flows. Also, the bump in the bed profile at cross section $1.1 \mathrm{~km}$ is rather local and not likely to act as some longitudinal wall under the water that would substantially mitigate transverse mixing by separating the flows.

In the next section, the mixing model is applied to these three flow cases to estimate reach-averaged transverse mixing coefficients and lengths for perfect/sufficient mixing. Then, a more detailed discussion of contrasting mixing processes is provided in section 6 .

\section{Application of the Transverse Mixing Model to the Field Cases}

\subsection{Implementation of the Model}

The first issue to consider for application of the transverse mixing model is whether the flows under investigation fulfill the assumptions behind Equation 4. Considering the time scale associated with the river hydrological regime, the discharges are considered constant enough during an event to assume a steady flow, so that longitudinal dispersion can be neglected. The two incoming tributaries have uniform conductivities: Indeed, conductivity standard deviations throughout the upstream cross sections are smaller than $0.5 \%$ in each case 
(a)
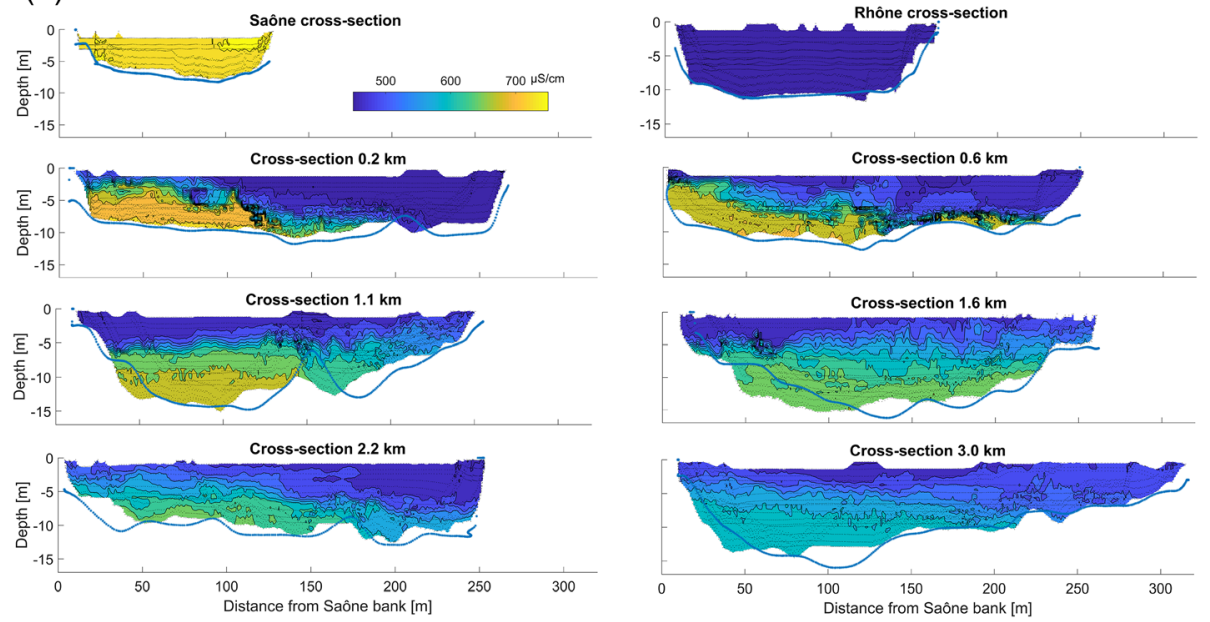

(b)
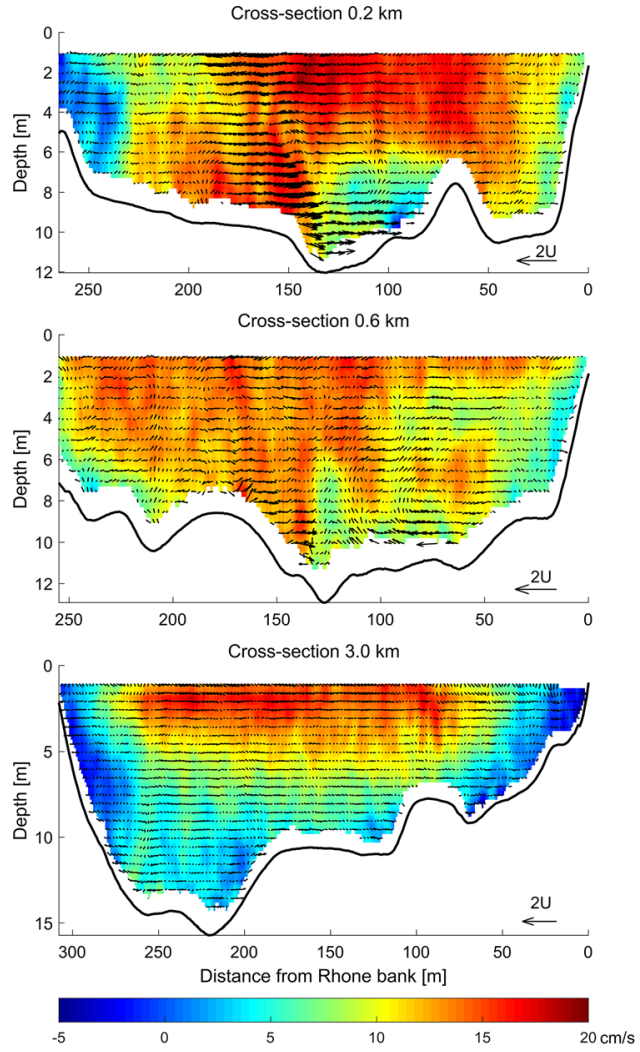

Figure 4. Measurements at various cross sections upstream and downstream of the Rhône-Saône confluence on 9 October (looking upstream, left bank on the right hand): (a) Conductivity contours. (b) Streamwise velocity with secondary flow vectors.

(see Figures 2a and 4a). As for the concentration along the vertical direction, the homogeneity condition is fairly fulfilled for March and May events (cf. Figures 2a and 3a). Thus, the conductivity data can be depth averaged to get transverse profiles and further estimate the transverse mixing coefficient. The application of the transverse mixing model is far more questionable for the October survey as the model assumptions are not fully met: The concentration is far from homogeneous along the vertical direction, and the crosswise velocity components have similar magnitudes as the mean streamwise velocity $U$. This means that mixing is not mainly transverse and governed by shear dispersion, and that important 3-D advective effects will be missed. 

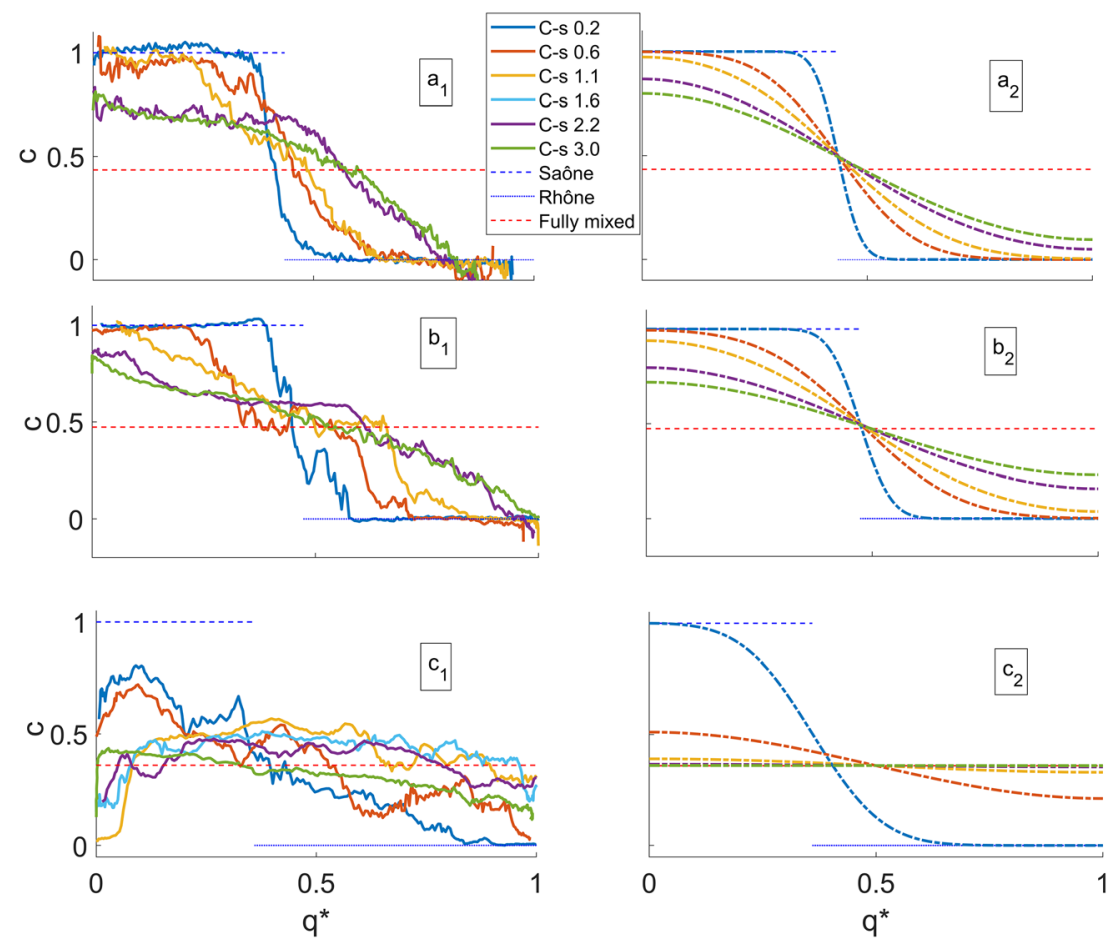

Figure 5. Transverse profiles of dimensionless, depth-averaged conductivity $c$ versus dimensionless cumulative discharge $q^{*}$ from the Saône bank on 8 March (a), 17 May (b), and 9 October (c) at the measured cross sections (C-s 0.2 to $3.0 \mathrm{~km}$ ): measured profiles (index 1, left) and profiles modeled using Equation 4 (index 2, right).

The theoretical transverse, depth-averaged concentration profiles can be computed at any longitudinal location $x$ using Equation 4. These profiles depend on the flow characteristics (mean velocity $U$, main stream and tributary discharges $Q_{\text {main }}$ and $Q_{\text {trib }}$ ) and on two unknown parameters: The transverse mixing coefficient $\varepsilon_{y}$ and the position $x_{0}$ of the virtual upstream cross section of the mixing. The mean velocity is derived from the ADCP data: $U=Q / S$ with $Q$ and $S$ the discharge and wetted area, respectively, of the flow downstream of the confluence. The wetted area $S$ is calculated as the mean over the cross sections downstream of the confluence. Positive values of $x_{0}$ indicate that mixing is delayed in the first reach downstream of the confluence by, for example, a civil engineering structure at the confluence, while $x_{0}<0$ indicates that mixing is enhanced in the first lengths of the combined reach, for example, because of the upstream lateral boundary layer development. Theoretical profiles are obtained by adjusting $\varepsilon_{y}$ and $x_{0}$ in order to fit the depth-averaged transverse concentration profiles provided by the field experiment, using least squares regression.

For comparison, all the data are plotted in dimensionless form in Figure 5: the dimensionless conductivity $c$ as a function of the dimensionless cumulative discharge $q^{*}=q / Q$ for the five cross sections located from 0 to $3 \mathrm{~km}$ downstream of the confluence. Dimensionless cumulative discharge $q^{*}$ is defined so that $q^{*}=0$ at the right bank (Saône) and $q^{*}=1$ at the left bank (Rhône). Note that the latter value is not always 1 because the discharges of the two rivers, especially the Rhône, can slightly vary along the duration of the survey (half a day), due to hydropeaking, and because of unavoidable discharge measurement errors.

\subsection{Results for March and May Surveys, With Limited Stratification Effect}

For the experiments of March and May, the concentration profiles (cf. Figures 5a and 5b) show the evolution of mixing between the two flows: With increasing $x$, the profiles tend toward straight, horizontal lines. The red dashed lines mark the theoretical complete mixing that would arise after a very long distance downstream of the confluence. Figure 5 reveals a fair agreement between the measured concentration profiles ( $a_{1}$ and $b_{1}$ ) and the corresponding solution of the analytical model $\left(a_{2}\right.$ and $\left.b_{2}\right)$, which is confirmed by the low values of root-mean-square error (RMSE) in Table 2. Table 2 also lists the values of the two parameters $\left(\varepsilon_{y}, x_{0}\right)$ obtained by applying least squares regression to the experimental data. Distance $x_{0}$ is positive for the 
Table 2

Mixing Efficiency Results Obtained From the Calibration of the Transverse Mixing Model (Equation 4)

\begin{tabular}{lccc}
\hline Date & $2018-03-08$ & $2018-05-17$ & $2018-10-09^{\mathrm{a}}$ \\
\hline$x_{0}(\mathrm{~m})$ & 150 & 121 & $131^{\mathrm{a}}$ \\
$\varepsilon_{y}\left(\mathrm{~m}^{2} / \mathrm{s}\right)$ & 0.81 & 1.39 & $1.6^{\mathrm{a}}$ \\
$\varepsilon_{y} /\left(\mathrm{Hu} u^{*}\right)$ & 1.34 & 2.21 & $17.8^{\mathrm{a}}$ \\
$R M S E($ non-dim) & 0.0072 & 0.0062 & $0.0154^{\mathrm{a}}$ \\
$\alpha$ & 0.313 & 0.322 & 0.351 \\
$L_{m} / b$ & 58 & 35 & $5^{\mathrm{a}}$ \\
$L_{m}(\mathrm{~km})$ & 16 & 9.7 & $1.4^{\mathrm{a}}$ \\
\hline
\end{tabular}

${ }^{\text {a }}$ The model should not apply for this case, because the problem is not mainly transverse. See text for explanation of the variables. two events, consistently with the presence of the drowned part of the spur that separates the two rivers and delays the mixing process. Values of $\varepsilon_{y}$ are made dimensionless as $\varepsilon_{y} /\left(H u^{*}\right)$ using the shear velocity $u^{*}$ calculated using the 1-D model of the Rhône River presented by Launay et al. (2019) for the discharges from Table 1 . The obtained values are $\varepsilon_{y} /\left(H u^{*}\right)=1.34$ and 2.21, which is close to the value (1.5) found by Bouchez et al. (2010) downstream of the Solimões and the Purús confluence. These values are higher than the range $0.166-0.18$ reported for a single, straight channel (e.g., Chau, 2000; Gualtieri \& Mucherino, 2007). In fact, the obtained values have the same order of magnitude as those for strongly meandering channels, in the range 1-3 (Rutherford, 1994). Values this large indicate that advective effects, rather than pure turbulent diffusion, are probably affecting mixing.

The presence of the harbor entrance at Section $3.0 \mathrm{~km}$ prevents from extending the field survey all the way to the length for complete mixing $L_{m}$ in an unmodified reach. Therefore, $L_{m}$ is estimated through Equation 6 and then made dimensionless relative to the mean river width $b$ downstream of the confluence (Table 2). For each campaign, the values of coefficient $\alpha$ (linking $L_{m}$ and $\epsilon_{y}$ through Equation 6) are computed based on Equation 4. For the March and May surveys, estimated $L_{m} / b$ ranges from 35 to 58 . This is the typical order of magnitude $\left(L_{m} / b=\mathrm{O}(100)\right)$ to be expected for slow mixing situations in large river confluences (e.g., Lane et al., 2008), among the wide range of values reported in the literature.

\subsection{Results for October Case, With a Strong Stratification Effect}

As explained above, the October situation (vertically stratified concentration) violates the basic assumptions of the transverse mixing model. Keeping this in mind, the model is nevertheless applied to depth-averaged concentrations to quantify the notional increase in transverse mixing efficiency for comparison with the real mixing cases. This application also illustrates the typical errors that could be made when overlooking vertical stratification effects.

The measured depth-averaged profiles in Figure $5 c_{1}$ strongly differ from the best fitted solutions of the analytical model (Figure $5 \mathrm{c}_{2}$ ). The fitted parameter $\varepsilon_{y} /\left(H u^{*}\right)=17.8$ (Table 2) is much higher than the highest values reported in the literature, that are for strongly meandering channels, and reported in the range 1-3 (Rutherford, 1994). Similarly, the value of the length for complete mixing is incredibly small, $L_{m}=1.4 \mathrm{~km}$, that is, $L_{m} / b=5.1$, a value much smaller than the order of 100 often reported in the literature downstream of river confluences. Distance $L_{m}=1.5 \mathrm{~km}$ is located between Cross Sections 1.1 and $1.6 \mathrm{~km}$ but Figure $4 \mathrm{a}$ reveals that the mixing is actually far from complete at these cross sections. The use of depth-averaged values to examine mixing in a strongly vertically stratified flow will yield results indicating "apparent" mixing even though the two confluent flows are not mixed. Typically, depth-averaged conductivity profiles in Figure $5 c_{1}$ appear fairly constant transversally when in fact the two flows remain essentially unmixed with one beneath the other as shown by strong vertical gradients of concentration (cf. Figure 4a). Part of the discharge is still composed of unmixed water originating from the Rhône River. The stratification of the flow encountered in this October case prevents from applying the analytical model based on transverse mixing alone in a relevant way.

\section{Discussion}

\subsection{What About Rapid Mixing?}

As also observed in previous studies, our findings show situations of "slow" and "rapid" mixing. The high-resolution conductivity contours of the three field surveys suggest that "slow" mixing happens when the mixing interface is vertical, while "rapid" mixing is associated with a transverse slumping motion of one flow under the other, resulting in a tilted mixing interface. In such situations, surface concentrations as well as depth-averaged concentrations appear to be well mixed laterally, which may hide the poor vertical mixing.

To the best of our knowledge, for low-angle, symmetrical confluences of large rivers, the only short lengths for complete mixing comparable to the $L_{m} / b=5.6$ predicted for the October survey were reported from 
surface photographs by Lane et al. (2008) with $L_{m} / b=\mathrm{O}(1)$. Quite rapid mixing was also reported in small, large-angle confluences: Gaudet and Roy (1995) characterize values of $L_{m} / b$ as small as 25, while Lewis and Rhoads (2015) estimate $L_{m} / b \approx 5-10$ from the evolution of the standard deviation of water temperatures in the first widths downstream of the confluence. However, such rapid mixing was not attributed to density effects but rather to helical motions generated by flow curvature (Lewis \& Rhoads, 2015) or bed discordance (Gaudet \& Roy, 1995), both effects that were not observed to be dominant at the Rhône-Saône confluence.

In contrast, the mixing processes observed by Lane et al. (2008) at the confluence between the Rio Parana and the Rio Paraguay share some similarities with our observations. Depending on the hydraulic conditions, they distinguished two mixing regimes: slow mixing, for which the length for complete mixing exceeds $400 \mathrm{~km}\left(L_{m} / b>143\right)$, and rapid mixing, for which the mixing is achieved $8 \mathrm{~km}\left(L_{m} / b=3\right)$ downstream of the confluence. The mixing rate was estimated from surface photographs and from ADCP backscatter data used to indirectly measure SPM concentration (as one river is highly concentrated in suspended sediments and the other one is not, the ADCP backscatter can be used as an indicator of mixing). In their rapid mixing case (May 2005 measurements), the denser water from the Rio Paraguay goes under the water from the Rio Parana in a similar way as the denser water from the Saône River goes under the water from the Rhône River in our rapid mixing case (October). However, bed discordance is opposite: The Rio Parana is entering the junction with a bottom elevation about 10-15 m above the bed of the Rio Paraguay, whereas the Saône bed stands about $5 \mathrm{~m}$ above the Rhône bed. This suggests that density difference may be more important than bed discordance to create such flow upwelling motion.

In such situations with homogeneous surface concentrations due to vertical stratification, the visual inspection of surface or satellite images may be misleading and suggest much shorter lengths than really required to complete full mixing. However, using more quantitative spectrometry methods (e.g., Umar et al., 2018), it may be possible to distinguish vertical stratification from mixing because vertical stratification is likely to produce a spectral signal at the surface that reflects the signature of the less dense flow upstream of the confluence, not an intermediate signal related to mixing. Surface observations of laterally unmixed flows over long distances remain meaningful as vertical stratification is then unlikely to happen without the less dense flow riding overtop the denser flow as the results of this study show.

\subsection{A Criterion for Predicting the Occurrence of Stratification?}

As stratification strongly impacts the mixing layer orientation and the mixing processes (as observed in October campaign), the ability to predict its occurrence would be invaluable. Table 3 lists the values of various criteria conceivable for this prediction, computed for our three surveys and-using assumptions listed in the table notes-for other surveys from the literature.

As reminded in section 1, the mixing of the two streams can be related first to shear dispersion. The intensity of shear-dominated dispersion depends on the nature of the mixing layer, as characterized by the dimensionless shear parameter $\lambda=\left|U_{\text {main }}-U_{\text {trib }}\right| /\left(U_{\text {main }}+U_{\text {trib }}\right)$ (Huerre \& Rossi, 1998; Proust et al., 2016), or, alternatively, by the velocity ratio $V R=U_{\text {trib }} / U_{\text {main }}$. When $\lambda$ is high enough, Kelvin-Helmoltz instability generates large 2-D coherent structures. When $\lambda$ is smaller than 0.3 , which is the case for the three surveys (see Table 3), smaller eddies with opposite rotation are shed from the junction corner. For this so-called wake mode (Constantinescu et al., 2011), the shear dispersion is relatively weak. Values of $\lambda$ for March and May surveys $(\lambda=0.2$ and 0.26 , respectively) are close to the 0.3 threshold, whereas the value for October survey $(\lambda=0.003)$ is much lower. While the mixing layer mode should be the same wake mode for all three surveys, this could suggest that shear-dominated dispersion is much weaker for October survey than for the other two surveys. Contrary to our data, $\lambda$ is always higher than 0.3 in the work by Ramón et al. (2013), with no connection with the appearance of stratification, and by Lane et al. (2008), independently of the intensity of the mixing. Therefore, it seems difficult to sort "slow" versus "rapid" mixing situations from the dimensionless shear parameter $\lambda$ only.

The momentum ratio $M^{*}$ can be related to the intensity of helical motion (Lewis \& Rhoads, 2015). It is defined here as the ratio of the tributary (Saône River) momentum divided by the main inflow (Rhône River) momentum. $M^{*}$ is slightly larger than 1 for the March campaign, higher for the May campaign but smaller than 1 for the October campaign. Yet the large-scale secondary motion is observed only for the 


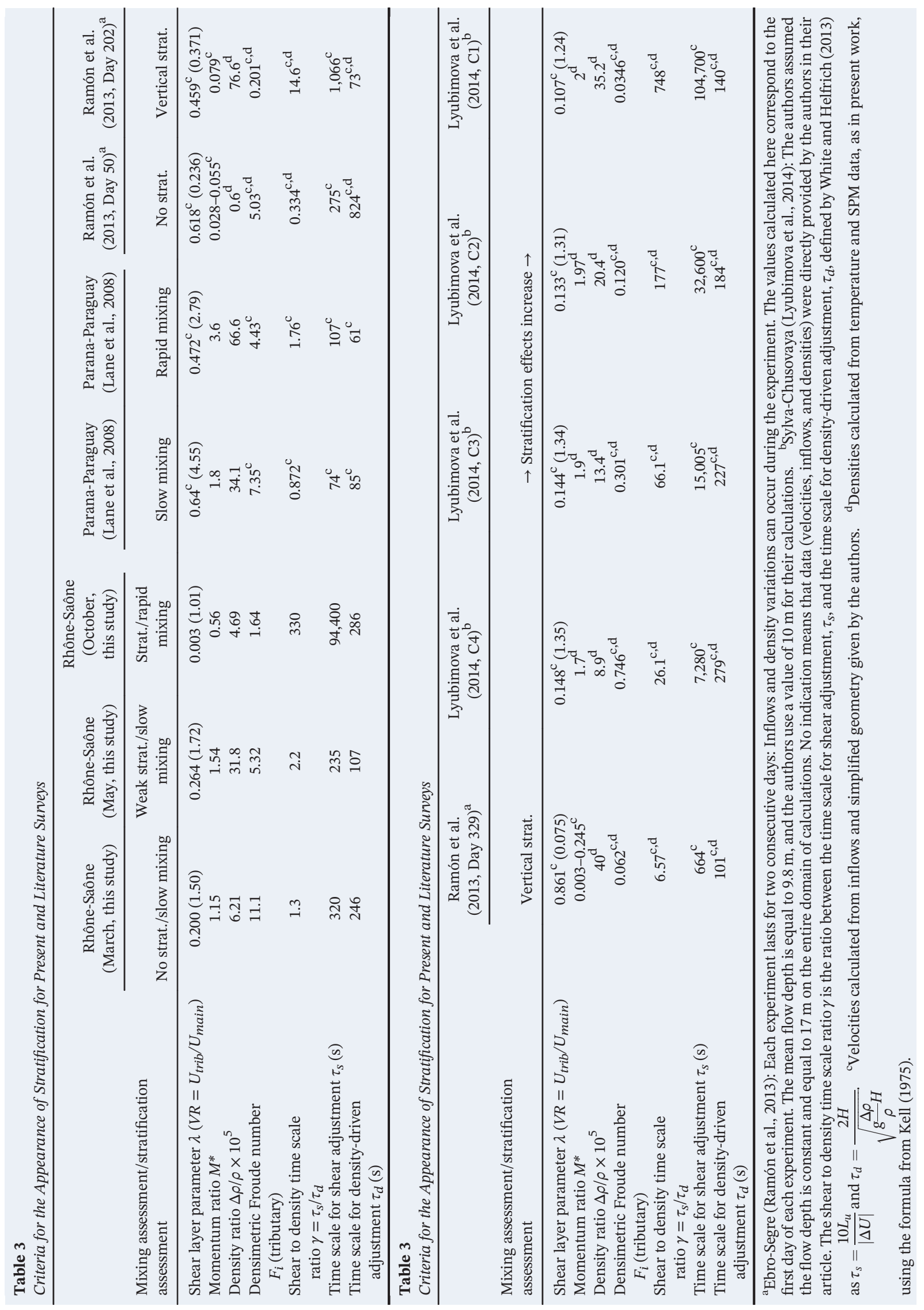


survey with $M^{*}<1$. The observed secondary motion is actually not helical motion but it is rather related to the lock-exchange-like mechanism identified by Horna Munoz et al. (2020). Indeed, the large-scale secondary motion is attributed to density effects rather than inertial effects, as it disappears as soon as the vertical stratification is achieved. Moreover, the orientation of the mixing layer is horizontal only for the case when $M^{*}<1$. This is contrary to the Parana-Paraguay confluence case reported by Lane et al. (2008), where the momentum ratio is smaller for slow mixing $\left(M^{*}=1.8\right)$ than for rapid mixing $\left(M^{*}=3.6\right)$.

As purely hydrodynamics criteria such as $\lambda$ or $M^{*}$ appear to inefficiently predict the vertical stratification, a criterion based on waters characteristics could be proposed. However, as already mentioned in section 4 , the differences between the three surveys cannot be explained only by changes in the relative density difference $\Delta \rho^{*}=\left(\rho_{\text {main }}-\rho_{\text {trib }}\right) / \rho$ between the two rivers (Table 1$)$, with $\rho$ the density of the fully mixed river downstream of the confluence. Indeed, the highest density difference (May survey) corresponds to a case with no stratification.

Following Ramón et al. (2013), a way for predicting the appearance of stratification is to compare the relative effects of both velocity and density differences. These authors propose to use the internal Froude number $F_{i}$ (also referred to as the densimetric Froude number in the literature) based on the tributary characteristics, which reads

$$
F_{i}=\frac{U_{t r i b}}{\left(g H \Delta \rho^{*}\right)^{1 / 2}}
$$

where $g\left(=9.81 \mathrm{~m} / \mathrm{s}^{2}\right)$ is the gravitational acceleration. The internal Froude number $F_{i}$ is the ratio of inertial forces divided by "the buoyancy of the side stream, parameterized in terms of the celerity of internal perturbations," equal to $\left(g H \Delta \rho^{*}\right)^{1 / 2}$. For " $F_{i} \gg 1$, the effect of density differences can be neglected, and the mixing interface between the confluent rivers remains largely vertical” (Ramón et al., 2013). Note that Equation 7 uses the mean velocity in the tributary, following Lewis and Rhoads (2015).

The internal Froude number $F_{i}$ already showed its ability to detect the presence of a vertical stratification on the Segre-Ebro confluence (Ramón et al., 2013): Vertical stratification is observed for low values of $F_{i}$, the transition being located in the range $0.2<F_{i}<5$. Based on eddy-resolving numerical simulations of the confluence studied by Lewis and Rhoads (2015), the recent results by Horna Munoz et al. (2020) confirm that density effects are weak for $F_{i}>5$ and strong for $F_{i}<2$. It is also the case in our surveys, with a transition located in the range $1.6<F_{i}<5.3$. For the scenarios simulated by Lyubimova et al. (2014) on the confluence of Chusovaya and Sylva rivers, the two inlets do not have uniform temperatures but the stratification appears more and more stable as and when $F_{i}$ decreases. For Lane et al. (2008) surveys, conclusions are less supportive. The two different mixing regimes at the confluence between the Rio Paraguay and the Rio Parana both correspond to $F_{i}>4$. This could be due to the strong bed discordance at the Paraguay-Parana confluence. However, when considering the detailed bathymetry proposed by the authors, it appears that a deep canal exists for the tributary flow in the downstream reach. It is tempting then to consider a depth of about $16 \mathrm{~m}$ to compute $F_{i}$, instead of the average $6 \mathrm{~m}$ in the reach. For the rapid mixing case, $F_{i}$ then equals to about 2 ; that is, $F_{i}$ lies in the transitional range indicated above for the disappearance of stratification. This arbitrary correction encourages the use of $F_{i}$ as a criterion to predict vertical stratification. It also underlines that its relevance may depend on the average values used for its computation and also on additional effects, as, for example, the strong bed discordance in the surveys from Lane et al. (2008).

An equivalent parameter is the Richardson number $R_{i}$. Cheng and Constantinescu (2018) consider $R_{i}=\left(U / U_{t r i b}\right) / F_{i}^{2}$ if we replace the thermal expansion coefficient by the reduced fluid density. This is equivalent to the use of an internal Froude number computed with the downstream reach characteristics. Then, using one scaling parameter or the other brings no significant changes to the orders of magnitude or to the conclusions, at least in the surveys considered in Table 3.

In their numerical study, White and Helfrich (2013) propose another criterion to compare the dynamics of a horizontal shear flow with horizontal density gradient. It is the shear to density time scale ratio $\gamma$ that compares the time scales for shear and density-driven adjustments, defined as 


$$
\gamma=\frac{5 L_{u}}{H} \frac{\left(g H \Delta \rho^{*}\right)^{1 / 2}}{\left|U_{\text {main }}-U_{\text {trib }}\right|}
$$

where $L_{u}$ is the length scale for the horizontal shear and $g \Delta \rho^{*}$ is the reduced gravity. Gualtieri et al. (2019) apply this criterion to the Solimões/Negro confluence. They find that the two time scales are comparable $(\gamma \approx 1)$ in the near field of the confluence and that density-driven adjustment becomes faster than shear adjustment farther downstream. The problem is that $\gamma$ is proportional to $L_{u}$, the length scale for the horizontal shear layer, which is not constant but increases with the distance from the confluence. We decide to evaluate $\gamma$ at the cross section where the shear layer scales with the flow depth, that is, for $L_{u}=H \approx 9.2 \mathrm{~m}$ for our three cases (cf. Table 1). The resulting values consistently reflect our observations of the two competing processes, as $\gamma$ is much higher than $1(\gamma=O(100))$ for the October case whereas $\gamma=O(1)$ for the two other cases (Table 3). Ratio $\gamma$ is also higher for May than for March as stratification was observed to start to develop in May survey. Indeed, May data (Figure 3) show clear evidence of buoyancy-driven effects in the regime $\gamma=O(1)$ where both transverse shear and gravitational tilting are important. Even $3 \mathrm{~km}$ downstream from the confluence, there are significant vertical gradients of conductivity, and the velocity fields show a transverse secondary circulation consistent with the gravitational effect.

With the same assumptions, $\gamma=O(1)$ for the two cases of Lane et al. (2008) but it is twice as large for the rapid mixing case $(\gamma=1.8)$ than for the slow mixing case $(\gamma=0.9)$. The variation is much smaller than for our surveys, but it seems consistent with a change in the rank of the two competing processes. For all the numerical cases simulated by Lyubimova et al. (2014), $\gamma$ is much larger than 1 and it gradually increases from 26 to 750 from their $\mathrm{C} 4$ to $\mathrm{C} 1$ experiments. Yet the authors report that stratification appears in all their cases but is much weaker for high flows (Cases C3 and C4) than low flows (Cases C1 and C2). As a conclusion, the shear to density time scale ratio $\gamma$ (White \& Helfrich, 2013) could be a relevant criterion for predicting the occurrence of stratification downstream of river confluences.

In the present state, it is difficult to identify the most efficient criterion to predict vertical stratification between $\gamma$ and $F_{i}$, and this should be the object of future studies. It is, however, interesting to note that for $\frac{L_{u}}{H}=$ constant in Equation 9 these two parameters are essentially identical (after taking the inverse of one of them). First, for these shallow flows in the immediate near field of the confluence where one should apply these criteria it is quite reasonable that $L_{u} / H=O(1)$. Second, in $\gamma$ the shear (through the main to tributary velocity difference) is used instead of the convective velocity $U_{\text {trib }}$. However, $\left|U_{\text {main }}-U_{\text {trib }}\right|$ is equal to $U_{\text {trib }}$ in a reference frame moving with $U_{\text {main }}$. Consequently, the two numbers have certainly the same physical meaning, although the dynamical explanation underlying $\gamma$ is explicit through the time scales for shear and density-driven adjustments. Actually, White and Helfrich (2013) show that $\gamma$ can be related to a horizontal Richardson number, suitable for horizontal shear flows with horizontal density gradient.

\subsection{Application to the Improvement of 1-D Models}

By definition, 1-D models assume that concentration is constant throughout a cross section. They are therefore unable to distribute unmixed flows at a downstream bifurcation or a water intake. As mentioned in section 1, the simple transverse mixing equations introduced in section 2.2 and calibrated at river confluences have a great potential for improving the distribution of solute and particulate concentrations and fluxes in 1-D models of branched river networks. Using the results of 1-D computations, the transverse mixing equations could be applied to predict transverse concentration profiles at each cross section downstream of a confluence. For such application to 1-D models, predicting depth-averaged concentration profiles would be sufficient to distribute fluxes in the branches of the model. If some portion of the discharge has to be diverted, for instance, toward a branch of a bifurcation, the corresponding flux and mean concentration can be computed by integrating the transverse concentration profile over that discharge. As already discussed, however, the transverse mixing model does not apply when vertical gradients of concentration are strong, that is, when mixing is not mainly transverse. In situations of upwelling motion and vertical stratification, concentrations are likely to be more homogeneous laterally than predicted with realistic values of the transverse mixing coefficient $\epsilon_{y}$.

To illustrate the potential and limitations of such a "1.5-D" modeling approach, we go back to the RhôneSaône confluence case. As shown in Figure 1, $3.5 \mathrm{~km}$ downstream of the confluence the Rhône River 


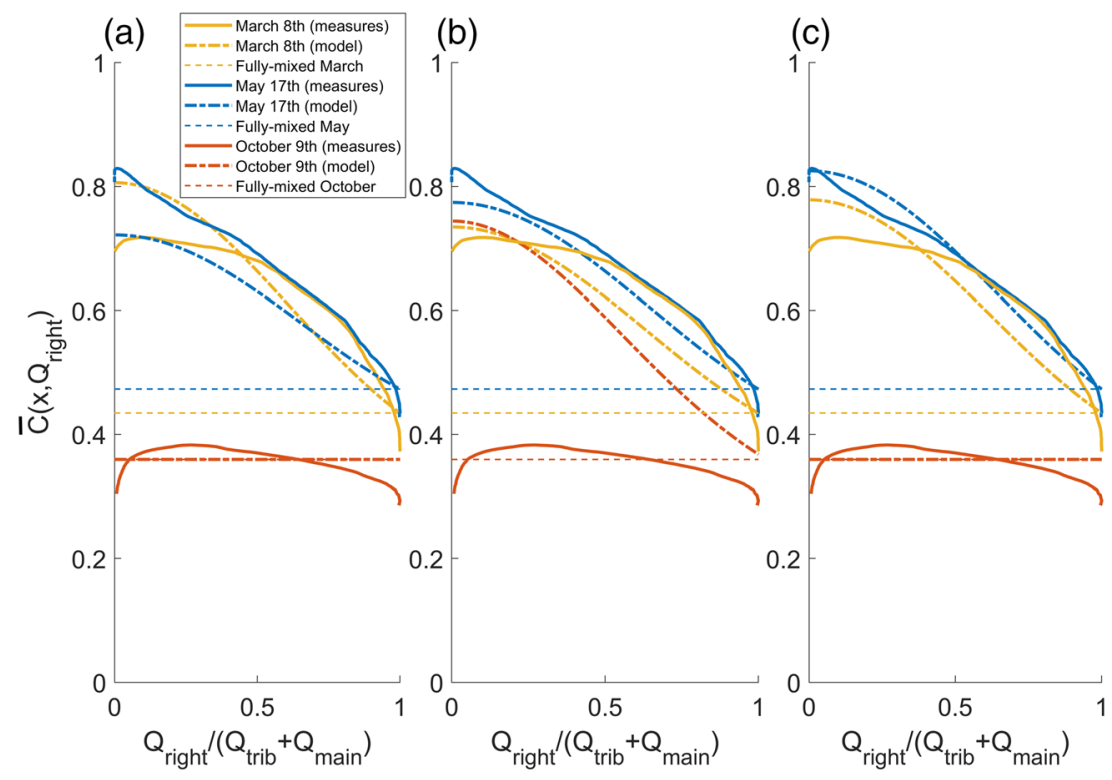

Figure 6. Dimensionless flow-averaged concentration, $\bar{C}\left(x, Q_{\text {right }}\right)$ in the right-hand part of the Rhône cross section at $x=3 \mathrm{~km}(x / b=10.9)$ downstream of the Rhône-Saône confluence, plotted as a function of the dimensionless cumulative discharge from the right bank, $Q_{\text {right }} /\left(Q_{t r i b}+Q_{\text {main }}\right)$, for (a) best fitted values of $\epsilon_{y} /\left(H u^{*}\right)$ (cf. Table 2), (b) $\epsilon_{y} /\left(H u^{*}\right)=2$, (c) $\epsilon_{y}=1 \mathrm{~m}^{2} / \mathrm{s}$. Horizontal dashed lines show the average concentrations that would be applied in traditional 1-D models.

splits into two channels, the dammed, bypassed Old Rhône and the navigation canal with a hydropower plant. More than 15 similar bifurcations exist along the Rhône River between Lake Geneva and the Mediterranean Sea (Dugué et al., 2015; Launay et al., 2019). A traditional 1-D model would compute different discharges, $Q_{\text {right }}$ and $Q_{\text {left }}$, for the two downstream branches but both concentrations would be equal to each other and equal to the cross-sectional average concentration upstream of the bifurcation. For better precision, the flow-averaged concentration in the right branch, $\bar{C}\left(x, Q_{\text {right }}\right)$, can be computed by integrating the transverse profile of concentration predicted by the advection-diffusion model (cf. Figure 5) over the discharge range of the right branch, from 0 to $Q_{\text {right }}$. The concentration in the left branch can be deduced easily from mass continuity.

Figure 6a shows that the right-branch average concentrations $\bar{C}\left(x=3 \mathrm{~km}, Q_{\text {right }}\right)$ predicted $3 \mathrm{~km}$ downstream of the confluence agree reasonably well with the observations for the whole range of flow diverted to the right branch (from $0 \%$ to $100 \%$ of Q). For the two slow-mixing events ( 8 March and 17 May), the two curves are similar and much higher than the mean concentrations that would be applied in traditional 1-D models: If half of the flow was diverted into the right branch $\left.Q_{\text {right }} /\left(Q_{\text {trib }}+Q_{\text {main }}\right)=0.5\right)$, the concentration (and flux) would be underestimated by the model by $25 \%$ or so. Reciprocally, the concentration (and flux) in the left branch would be overestimated by the same amount. For the fast-mixing event (9 October), the predicted concentration profile is constant as the mixing coefficient $\epsilon_{y}$ is set to a very high value; departures from the observed concentrations are then small because transverse mixing is almost complete at Kilometer 3, even though the vertical mixing processes are missed by the model, as discussed before.

These results are encouraging for improving the 1-D simulation of fluxes in river networks with confluences and bifurcations, at least when vertical stratification does not occur. However, they were obtained using the best fitted mixing coefficients $\epsilon_{y}$ for each of the three surveys (Figure 6a). The results obtained with a constant value of the dimensionless mixing coefficient $\epsilon_{y} /\left(H u^{*}\right)=2$ (cf. Figure $6 \mathrm{~b}$ ), which is more or less an average of March and May values (Table 2), are similarly acceptable and still much more accurate than the perfectly mixed average concentrations that would be applied in traditional 1-D models, except for the October case (rapid mixing) for which transverse mixing is underestimated. Finally, the results obtained 
with a constant, average value of the mixing coefficient $\epsilon_{y}=1 \mathrm{~m}^{2} / \mathrm{s}$ (cf. Figure $6 \mathrm{c}$ ) are good for all three surveys. The better results for the October survey may be undeserved since the conditions of application of the advection-diffusion model are not met, as already discussed.

The mixing coefficient could also be made variable using predictive formulas (e.g., Huai et al., 2018) as the 1-D model can provide the input parameters of the upstream branches of the confluence. If necessary, fast-mixing situations could be detected by computing the shear to density time scale ratio $\gamma$ from the velocities and densities in the two upstream branches, and testing if $\gamma>1$. Computing the water density would, however, require the temperature and suspended sediment concentration for both tributaries, which is not available in all 1-D models. Also, the criterion based on $\gamma$ or the internal Froude number remains to be validated and possibly improved, as discussed in the previous section.

\section{Conclusions}

This paper reports the experimental findings of three high-resolution in situ surveys conducted at the Rhône-Saône confluence in France for various hydraulic conditions, to investigate the mixing processes developing in the near field of a medium-sized, symmetrical, low-angle river confluence. Like in other studies, contrasting slow mixing and fast mixing situations were observed depending on the conditions of each survey. The initiation of rapid transverse mixing, corresponding to the onset of a horizontal mixing interface, remains to be better understood and quantified. Moreover, apparently rapid transverse mixing actually comes with strong vertical concentration gradients (stratification), which may be missed when surface or satellite images are analyzed qualitatively. The internal Froude number with a $2-5$ threshold value (or the similar horizontal Richardson number) seems to be a promising criterion to predict the orientation of the mixing interface and the occurrence of vertical stratification. The internal Froude number is, however, sensitive to the average values required for its computation. The shear to density time scale ratio $\gamma$ appears an equally suitable predictor of the shear and density-driven adjustment intensities. Further investigation is required to definitely decide between these two criteria and assess their respective relevance and the corresponding thresholds.

When vertical stratification does not occur, cross-sectional profiles of depth-averaged concentrations can be predicted acceptably using an analytical solution of the 2-D advection-diffusion equation. As discussed in this study, this is an encouraging perspective for improving the distribution of solute and particulate fluxes in 1-D hydrodynamic models of branched river networks. However, the situations of rapid mixing due to vertical stratification should be detected and accounted for. More advanced models than the transverse mixing equations introduced in this paper would be required to capture the impact of gravitational slumping motion (as observed in this study) on transverse and vertical mixing, as well as the impact of other advective effects like helical motion related to flow curvature and strong upwelling motion related to bed discordance.

Our findings compare reasonably well with other experimental and numerical studies of similar configurations of large, low-angle river confluences, which are likely to be affected by density-driven effects too. The range of conditions for which density control on mixing efficiency may be significant remains to be determined more precisely. As such, this research calls for future observational effort on the mixing of waters downstream of river confluences with a broader range of site configurations and hydrological conditions. The modern instrumentation (ADCP, GPS, and CTD loggers) deployed in this study provided high-resolution measurements of the bed geometry, flow structure, and water mixing at reasonable cost. It is certainly an opportunity to revisit the low-resolution experimental data sets dating back to the 1960s and 1970s-using point current meters and water samples-and to improve the calibration and validation of transverse mixing formulas that are still needed in modern computational codes.

\section{Appendix A: Calculation of Coefficient $\alpha$ (See Equation 6), From Rutherford (1994)}

A fully developed 2-D channel flow is considered: Its dimensions (transverse discharge $q$ and longitudinal distance $x$ ) are made dimensionless through the variables $q^{*}=q / Q$ and $x^{*}=x \varepsilon_{y} \psi U H^{2} / Q^{2}$. A surface source of pollution is considered, which in 2-D corresponds to a linear pollution of dimensionless width $Q^{*}$ trib $=Q_{\text {trib }} / Q$. At $x^{*}=0$, the source of pollution is homogeneously distributed between $q^{*}=0$ and $q^{*}=Q^{*}{ }_{\text {trib }}$. 
(a)

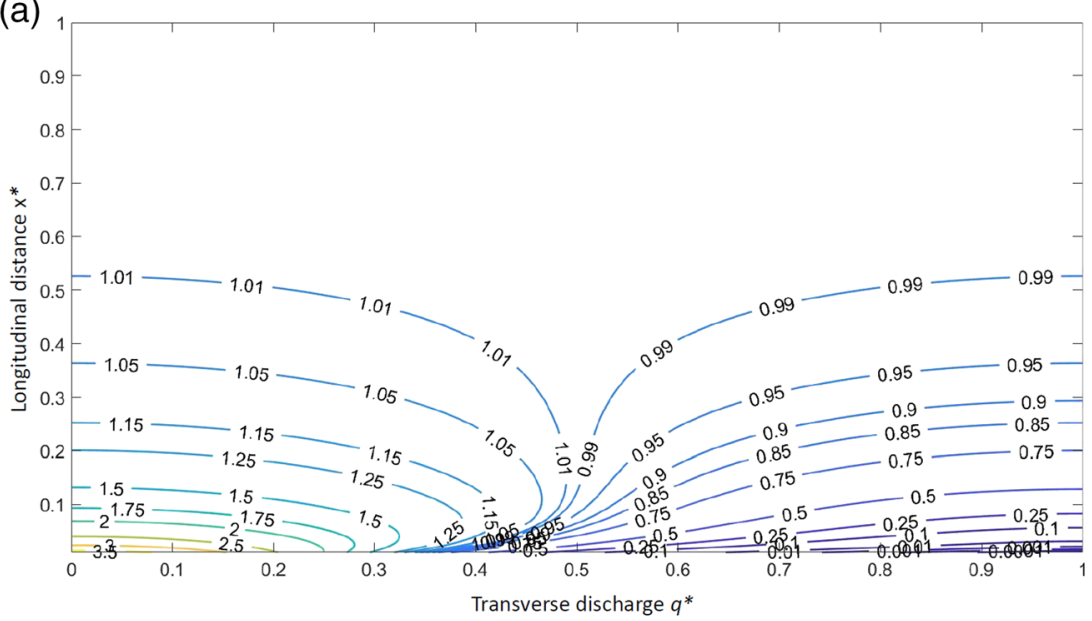

(b)

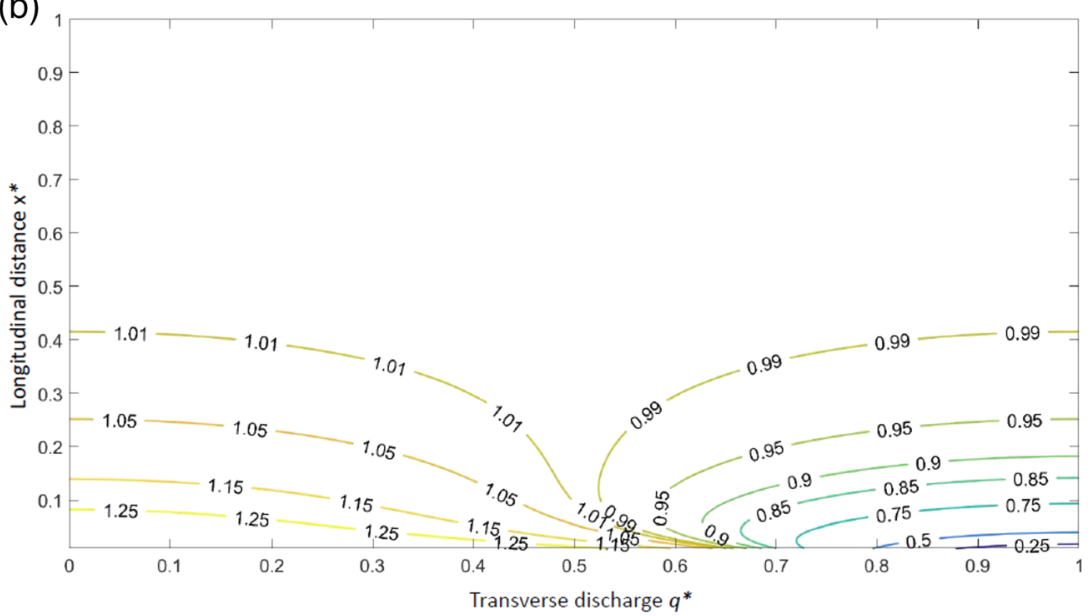

Figure 7. Isoconcentration $c / c_{u}$ contour plots computed for $Q_{\text {trib }}^{*}=0.25$ (a) and $Q_{\text {trib }}^{*}=0.75$ (b). The value of the coefficient $\alpha$ can be read at the intersection between the left vertical axis and the $c / c_{u}=1.05$ contour line

The goal is to determine the distribution of pollutant concentration across the channel in order to estimate the coefficient $\alpha$, which links the length for complete mixing to the transverse mixing coefficient $\epsilon_{y}$ (Equation 6).

Another way to write Equation 4 is to use the error function $\operatorname{erf}(x)=\frac{1}{\sqrt{\pi}} \int_{0}^{x} \exp \left(-t^{2}\right) d t$. Then, the distribution of pollutant concentration across the channel can be written as

$$
\begin{aligned}
c\left(x^{*}, q^{*}\right) & =\frac{1}{2}\left[\operatorname{erf}\left(\frac{q^{*}+Q_{t r i b}^{*}}{2 \sqrt{x^{*}}}\right)-\operatorname{erf}\left(\frac{q^{*}-Q_{t r i b}^{*}}{2 \sqrt{x^{*}}}\right)\right] \\
& +\frac{1}{2} \sum_{n=1}^{N}\left[\operatorname{erf}\left(\frac{2 n+q^{*}+Q_{\text {trib }}^{*}}{2 \sqrt{x^{*}}}\right)-\operatorname{erf}\left(\frac{2 n+q^{*}-Q_{t r i b}^{*}}{2 \sqrt{x^{*}}}\right)+\operatorname{erf}\left(\frac{2 n-q^{*}+Q_{t r i b}^{*}}{2 \sqrt{x^{*}}}\right)-\operatorname{erf}\left(\frac{2 n-q^{*}-Q_{t r i b}^{*}}{2 \sqrt{x^{*}}}\right)\right]
\end{aligned}
$$

The coefficient $\alpha$ in Equation 6 is defined so that $0.95 c_{u}<c\left(x^{*}>\alpha, q^{*}\right)<1.05 c_{u}$, whatever transverse position $q^{*}$ is taken, which means that the transverse mixing is complete considering the $5 \%$ criterion. At $x^{*}=\alpha$, the concentration is maximum at the edge of the upstream pollutant source, that is, $c\left(x^{*}=\alpha, q^{*}=0\right)=1.05 c_{u}$ (see Figure 7).

The equation to be solved numerically to get the value of $\alpha$ is the following: 


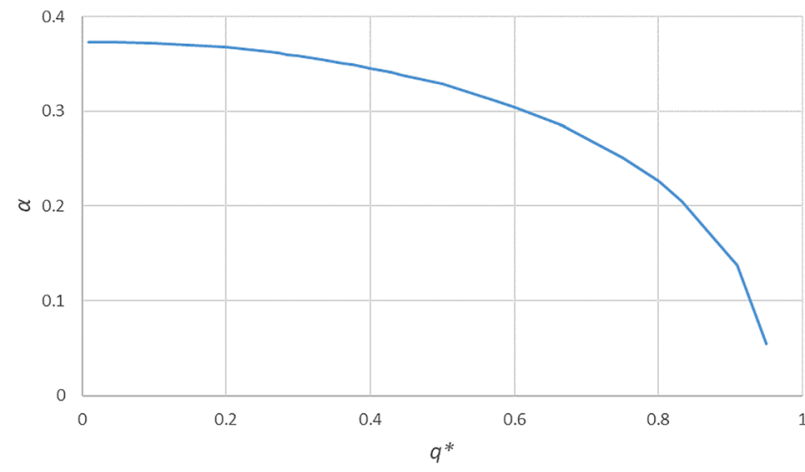

Figure 8. Coefficient $\alpha$ versus the dimensionless width $q^{*}$ of the pollution source.

$$
\begin{aligned}
c(\alpha, 0) & =\operatorname{erf}\left(\frac{Q_{\text {trib }}^{*}}{2 \sqrt{\alpha}}\right)+\sum_{n=1}^{N}\left[\operatorname{erf}\left(\frac{2 n+Q_{\text {trib }}^{*}}{2 \sqrt{\alpha}}\right)-\operatorname{erf}\left(\frac{2 n-Q_{\text {trib }}^{*}}{2 \sqrt{\alpha}}\right)\right] \\
& =1.05 c_{u} .
\end{aligned}
$$

Thus, coefficient $\alpha$ depends on the width of the pollution source $Q_{\text {trib }}^{*}$, which, in the case of a confluence, depends directly on the discharge ratio between both inflows. In a more general case, it also depends on the position of the source of pollution $q_{0}$, which is not taken into account here. Of course, the value of $\alpha$ depends on the mixing criterion. For example, the condition for a $1 \%$ criterion would be $c(\alpha, 0)=1.01 c_{u}$, which is a more severe criterion; the value of $\alpha$ would then be greater than for the $5 \%$ criterion. Numerically, the solution also depends on the number of mirrors $(4 N+1)$ in the image method and the precision of the chosen grids for discretizing the $x^{*}$ and $q^{*}$ axes. It is observed that with $N=2$ (i.e., nine mirrors), a precision of four digits is already obtained on $\alpha$.

It can be noticed that the curve shown on Figure 8 is not symmetrical with respect to $Q_{t r i b}^{*}=0.5$, which means that mixing a pollution source occupying $25 \%$ of the channel with the rest of the flow is not equivalent to mixing a pollution source occupying $75 \%$ of the channel. Indeed, the final concentration, though dimensionless, is not the same in those two cases because the discharges; hence, the fluxes are not the same in the two confluent flows. Thus, the transverse distributions of concentration for $Q_{t r i b}^{*}=0.25$ and $Q_{t r i b}^{*}=0.75$ (Figure 7) are not symmetrical and give different values of $\alpha$ (which can be read on the left axis, at the crossing with the $c=1.05 c_{u}$ curve). Also, a $15 \%$ criterion for $Q_{t r i b}^{*}=0.25$, for instance, is equivalent to a $5 \%$ criterion for $Q_{t r i b}^{*}=0.75$. This is because the concentration is 3 times larger in the latter case $\left(Q_{\text {trib }}^{*}=0.75\right)$ than in the former case $\left(Q_{t r i b}^{*}=0.25\right)$ due to the different distributions of discharges, hence fluxes between the two confluent flows.

\section{Data Availability Statement}

The data are available for download at Zenodo (https://zenodo.org/record/3877520).

\section{Acknowledgments}

We are very grateful to the Associate Editor, Carlo Gualtieri, Bruce Rhoads, and the third anonymous reviewer for their insightful comments that substantially helped us to improve our manuscript. We also wish to thank Mickaël Lagouy and Alexis Buffet (INRAE) for their invaluable technical support before, during and after the experiments. Sébastien Pouchoulin held a doctoral fellowship from Région Auvergne-Rhône-Alpes. This study was conducted within the Rhône Sediment Observatory (OSR), a multipartner research program funded through the Plan Rhône by the European Regional Development Fund (ERDF, contract: CNRS-144140), Agence de l'eau RhôneMéditerranée-Corse (France, contract: 2018 1063), Compagnie Nationale du Rhône (CNR), EDF, and three regional councils (Région Auvergne-RhôneAlpes, PACA, and Région Occitanie Pyrénées-Méditerranée). This work was performed within EUR H2O'Lyon (ANR-17-EURE-0018) of Université de Lyon (UdL), as part of the program "Investissements d'Avenir" operated by the French National Research Agency (ANR).

\section{References}

Beltaos, S. (1979). Transverse mixing in natural streams. Canadian Journal of Civil Engineering, 6(6), 575-591. https://doi.org/10.1139/ 179-070

Beltaos, S. (1980). Transverse mixing tests in natural streams. Journal of the Hydraulics Division, 106(10), 1607-1625.

Beltaos, S., \& Arora, V. K. (1988). An explicit algorithm to simulate transient transverse mixing in rivers. Canadian Journal of Civil Engineering, 15(6), 964-976. https://doi.org/10.1139/188-128

Biron, P., Best, J. L., \& Roy, A. G. (1996). Effects of bed discordance on flow dynamics at open channel confluences. Journal of Hydraulic Engineering, 122(12), 676-682. https://doi.org/10.1061/(asce)0733-9429(1996)122:12(676)

Biron, P. M., Buffin-Bélanger, T., \& Martel, N. (2019). Three-dimensional turbulent structures at a medium-sized confluence with and without an ice cover. Earth Surface Processes and Landforms, 44(15), 3042-3056. https://doi.org/10.1002/esp.4718

Biron, P. M., Ramamurthy, A. S., \& Han, S. (2004). Three-dimensional numerical modeling of mixing at river confluences. Journal of Hydraulic Engineering, 130(3), 243-253. https://doi.org/10.1061/(ASCE)0733-9429(2004)130:3(243)

Bouchez, J., Lajeunesse, E., Gaillardet, J., France-Lanord, C., Dutra-Maia, P., \& Maurice, L. (2010). Turbulent mixing in the Amazon River: The isotopic memory of confluences. Earth and Planetary Science Letters, 290(1-2), 37-43. https://doi.org/10.1016/j.epsl.2009.11.054

Bradbrook, K. F., Lane, S. N., Richards, K. S., Biron, P., \& Roy, A. G. (2001). Role of bed discordance at asymmetrical open-channel confluences. Journal of Hydraulic Engineering, 127(5), 351-368. https://doi.org/10.1061/(ASCE)0733-9429(2001)127:5(351)

Chau, K. W. (2000). Transverse mixing coefficient measurements in an open rectangular channel. Advances in Environmental Research, 4(4), 287-294. https://doi.org/10.1016/S1093-0191(00)00028-9

Cheng, Z., \& Constantinescu, G. (2018). Stratification effects on flow hydrodynamics and mixing at a confluence with a highly discordant bed and a relatively low velocity ratio. Water Resources Research, 54, 4537-4562. https://doi.org/10.1029/2017WR022292

Constantinescu, G., Miyawaki, S., Rhoads, B., Sukhodolov, A., \& Kirkil, G. (2011). Structure of turbulent flow at a river confluence with momentum and velocity ratios close to 1 : Insight provided by an eddy-resolving numerical simulation. Water Resources Research, 47 , W05507. https://doi.org/10.1029/2010WR010018

Constantinescu, G., Shinjiro, M., Rhoads, B., \& Sukhodolov, A. (2016). Influence of planform geometry and momentum ratio on thermal mixing at a stream confluence with a concordant bed. Environmental Fluid Mechanics, 16, 845-873. https://doi.org/10.1007/s10652-0169457-0

Dugué, V., Walter, C., Andriès, E., Launay, M., Le Coz, J., Camenen, B., Faure, J.-B. (2015). Accounting for hydropower schemes' operation rules in the 1D hydrodynamic modeling of the Rhône River from Lake Geneva to the Mediterranean Sea (pp. 1-9). Paper presented at eProceedings of the 36th IAHR World Congress, The Hague, The Netherlands. 
El Kadi Abderrezzak, K., Ata, R., \& Zaoui, F. (2015). One-dimensional numerical modelling of solute transport in streams: The role of longitudinal dispersion coefficient. Journal of Hydrology, 527, 978-989. https://doi.org/10.1016/j.jhydrol.2015.05.061

Fischer, H. B., List, J. E., Koh, C. R., \& Imberger, J. (1979). Mixing in inland and coastal waters. New York: Elsevier.

Gaspar, E. (1987). Modern trends in tracer hydrology. Boca Raton: CRC Press.

Gaudet, J. M., \& Roy, A. G. (1995). Effect of bed morphology on flow mixing length at river confluences. Letters to Nature, 373(6510), 138-139. https://doi.org/10.1038/373138a0

Gualtieri, C., Filizola, N., de Oliveira, M., Santos, A. M., \& Ianniruberto, M. (2018). A field study of the confluence between negro and Solimões Rivers. Part 1: Hydrodynamics and sediment transport. Comptes Rendus Geoscience, 350(1-2), 31-42. https://doi.org/10.1016/j. crte.2017.09.015

Gualtieri, C., Ianniruberto, M., \& Filizola, N. (2019). On the mixing of rivers with a difference in density: The case of the Negro/Solimões confluence, Brazil. Journal of Hydrology, 578, 124029. https://doi.org/10.1016/j.jhydrol.2019.124029

Gualtieri, C., \& Mucherino, C. (2007). Transverse turbulent diffusion in straight rectangular channels. Paper presented at 5th International Symposium on Environmental Hydraulics (ISEH 2007), Tempe, USA.

Herrero, H. S., Lozada, J. M. D., Garcia, C. M., Szupiany, R. N., Best, J., \& Pagot, M. (2018). The influence of tributary flow density differences on the hydrodynamic behavior of a confluent meander bend and implications for flow mixing. Geomorphology, 304, 99-112. https://doi.org/10.1016/j.geomorph.2017.12.025

Horna Munoz, D., Constantinescu, G., Rhoads, B., Lewis, Q., \& Sukhodolov, A. (2020). Density effects at a concordant bed natural river confluence. Water Resources Research, 56, e2019WR026217. https://doi.org/10.1029/2019WR026217

Huai, W., Shi, H., Yang, Z., \& Zeng, Y. (2018). Estimating the transverse mixing coefficient in laboratory flumes and natural Rivers. Water, Air, and Soil Pollution, 229, 1-17. https://doi.org/10.1007/s11270-018-3893-Z

Huerre, P., \& Rossi, M. (1998). Hydrodynamic instabilities in open flows. Hydrodynamics and Nonlinear Instabilities, 81-294. https://doi. org/10.1017/CBO9780511524608.004

Jung, S. H., Seo, I. W., Kim, Y. D., \& Park, I. (2019). Feasibility of velocity-based method for transverse mixing coefficients in river mixing analysis. Journal of Hydraulic Engineering, 145(11), 04019040.

Kell, G. S. (1975). Density, thermal expansivity, and compressibility of liquid water from $0^{\circ}$ to $150^{\circ} \mathrm{C}$ : Correlations and tables for atmospheric pressure and saturation reviewed and expressed on 1968 temperature scale. Journal of Chemical and Engineering Data, 20(1), 97-105. https://doi.org/10.1021/je60064a005

Lane, S. N., Bradbrook, K. F., Richards, K. S., Biron, P. M., \& Roy, A. G. (2000). Secondary circulation cells in river channel confluences: Measurement artefacts or coherent flow structures? Hydrological Processes, 14, 2047-2071. https://doi.org/10.1002/1099-1085(20000815/ 30)14:11/12<2047::AID-HYP54>3.0.CO;2-4

Lane, S. N., Parsons, D. R., Best, J. L., Orfeo, O., Kostaschuk, R. A., \& Hardy, R. J. (2008). Causes of rapid mixing at a junction of two large rivers: Rio Parana and Rio Paraguay, Argentina. Journal of Geophysical Research, 113, F02019. https://doi.org/10.1029/ 2006JF000745

Laraque, A., Guyot, J. L., \& Filizola, N. (2009). Mixing processes in the Amazon River at the confluences of the negro and Solimoes Rivers, Encontro das Aguas, Manaus, Brazil. Hydrological Processes, 23(22), 3131-3140. https://doi.org/10.1002/hyp.7388

Launay, M., Dugué, V., Faure, J.-B., Coquery, M., Camenen, B., \& Le Coz, J. (2019). Numerical modelling of the suspended particulate matter dynamics in a regulated river network. Science of the Total Environment, 665, 591-605. https://doi.org/10.1016/j. scitotenv.2019.02.015

Lewis, Q. W., \& Rhoads, B. L. (2015). Rates and patterns of thermal mixing at a small stream confluence under variable incoming flow conditions. Hydrological Processes, 29(20), 4442-4456. https://doi.org/10.1002/hyp.10496

Lyubimova, T., Lepikhin, A., Konovalov, V., Parshakova, Y., \& Tiunov, A. (2014). Formation of the density currents in the zone of confluence of two rivers. Journal of Hydrology, 508, 328-342. https://doi.org/10.1016/j.jhydrol.2013.10.041

Mehta, R. D. (1991). Effect of velocity ratio on plane mixing layer development: Influence of the splitter plate wake. Experiments in Fluids, 10(4), 194-204. https://doi.org/10.1007/BF00190389

Moody, J. A. (1995). Observations of mixing processes downstream from the confluence of the Mississippi and St. Croix rivers. Geophysical Monograph Series, 94, 275-286.

Parsons, D. R., Jackson, P. R., Czuba, J. A., Engel, F. L., Rhoads, B. L., Oberg, K. A., et al. (2013). Velocity mapping toolbox (VMT): A processing and visualization suite for moving-vessel ADCP measurements. Earth Surface Processes and Landforms, 38(11), 1244-1260. https://doi.org/10.1002/esp.3367

Pouchoulin, S., Ramos, P. X., Mignot, E., Schindfessel, L., De Mulder, T., \& Riviere, N. (2018). Discussion of “Tang, H., Zhang, H., \& Yuan, S. (2018). Hydrodynamics and contaminant transport on a degraded bed at a 90-degree channel confluence. Environmental Fluid Mechanics, 18(2), 443-463”. Environmental Fluid Mechanics, 18(5), 1293-1295. https://doi.org/10.1007/s10652-018-9612-x

Poulier, G., Launay, M., Le Bescond, C., Thollet, F., Coquery, M., \& Le Coz, J. (2019). Combining flux monitoring and data reconstruction to establish annual budgets of suspended particulate matter, mercury and PCB in the Rhône River from Lake Geneva to the Mediterranean Sea. Science of the Total Environment, 658, 457-473. https://doi.org/10.1016/j.scitotenv.2018.12.075

Proust, S., Fernandes, J. N., Leal, J. B., Rivière, N., \& Peltier, Y. (2016). Mixing layer and coherent structures in compound channel flows: Effects of transverse flow, velocity ratio and vertical confinement. Water Resources Research, 53, 3387-3406. https://doi.org/10.1002/ 2016WR019873

Ramón, C. L., Hoyer, A. B., Armengol, J., Dolz, J., \& Rueda, F. J. (2013). Mixing and circulation at the confluence of two rivers entering a meandering reservoir. Water Resources Research, 49, 1429-1445. https://doi.org/10.1002/wrer.20131

Rathbun, R. E., \& Rostad, C. E. (2004). Lateral mixing in the Mississippi River below the confluence with the Ohio River. Water Resources Research, 40, W05207. https://doi.org/10.1029/2003WR002381

Rhoads, B. L. (1996). Mean structure of transport-effective flows at an asymmetrical confluence when the main stream is dominant. In P. J. Ashworth, S. J. Bennett, J. L. Best, \& S. J. McLelland (Eds.), Coherent flow structures in open channels (pp. 491-517). Chichester: John Wiley \&Sons Ltd.

Rhoads, B. L., \& Johnson, K. (2018). Three-dimensional flow structure, morphodynamics, suspended sediment, and thermal mixing at an asymmetrical river confluence of a straight tributary and curving main channel. Geomorphology, 323, 51-69. https://doi.org/10.1016/j. geomorph.2018.09.009

Rhoads, B. L., \& Kenworthy, S. T. (1995). Flow structure at an asymmetrical stream confluence. Geomorphology, 11(4), 273-293. https://doi. org/10.1016/0169-555X(94)00069-4 
Rhoads, B. L., \& Kenworthy, S. T. (1999). On secondary circulation, helical motion and Rozovskii-based analysis of time-averaged twodimensional velocity fields at confluences. Earth Surface Processes and Landforms, 24(4), 369-375. https://doi.org/10.1002/(SICI)10969837(199904)24:4<369::AID-ESP983>3.0.CO;2-F

Rhoads, B. L., \& Sukhodolov, A. N. (2001). Field investigation of three-dimensional flow structure at stream confluences. Water Resources Research, 37(9), 2393-2410. https://doi.org/10.1029/2001WR000316

Rutherford, J. C. (1994). River mixing. Chichester, UK: Wiley.

Shakibainia, A., Tabatai, M. R. M., \& Zarrati, A. R. (2010). Three-dimensional numerical study of flow structure in channel confluences Canadian Journal of Civil Engineering, 37, 772-781. https://doi.org/10.1139/L10-016

Sukhodolov, A. N., \& Sukhodolova, T. A. (2019). Dynamics of flow at concordant gravel bed river confluences: Effects of junction angle and momentum flux ratio. Journal of Geophysical Research: Earth Surface, 124, 588-615. https://doi.org/10.1029/2018JF004648

Umar, M., Rhoads, B. L., \& Greenberg, J. A. (2018). Use of multispectral satellite remote sensing to assess mixing of suspended sedimen downstream of large river confluences. Journal of Hydrology, 556, 325-338. https://doi.org/10.1016/j.jhydrol.2017.11.026

White, B. L., \& Helfrich, K. R. (2013). Rapid gravitational adjustment of horizontal shear flows. Journal of Fluid Mechanics, $721,86-117$. https://doi.org/10.1017/jfm.2013.41

Yotsukura, N., Cobb, E. D. (1972). Transverse diffusion of solutes in natural streams. Geological Survey Professional Paper 582-C, 19 p.

Yotsukura, N., \& Sayre, W. W. (1976). Transverse mixing in natural channels. Water Resources Research, 12(4), 695-704. https://doi.org/ 10.1029/WR012i004p00695 